ANUARIO DE EstUdios MEDIEVALES

51/2, julio-diciembre de 2021, pp. 629-660

ISSN 0066-506

https://doi.org/10.3989/aem.2021.51.2.05

\title{
BEATRIZ DE LAURIA Y JÉRICA, UNA DAMA VALENCIANA EN LA ANDALUCÍA DEL SIGLO XIV
}

\author{
BEATRIZ DE LAURIA Y JÉRICA, A VALENCIAN NOBLEWOMAN \\ IN FOURTEENTH-CENTURY ANDALUSIA
}

JUAN LUIS CARRIAZO RUBIO

Universidad de Huelva

https://orcid.org/0000-0002-4946-9796

\begin{abstract}
Resumen: El matrimonio, en 1335, de Beatriz de Lauria con el segundo señor de Marchena constituye un acontecimiento fundamental en el proceso de consolidación del linaje de los Ponce de León andaluces. Al mismo tiempo, modifica por completo las circunstancias vitales de Beatriz, no solo por el cambio de reino que supone su traslado de Valencia a Sevilla, sino también por las complejas relaciones entre Castilla y Aragón durante las décadas centrales del siglo XIV. Todo ello afectó a sus aspiraciones señoriales en territorio valenciano, dificultadas por la actuación de sus hermanos Jaime y Pedro de Jérica. El hecho de que sobreviviera a su esposo durante más de veinte años nos permite analizar su actuación en el contexto andaluz, aspecto poco conocido y de gran interés en un reinado, como el de Pedro I de Castilla, tan adverso para los grandes linajes sevillanos.
\end{abstract}

Palabras clave: nobleza; linaje; régimen señorial; Ponce de León; Guzmán; Jérica/Xèrica.

Abstract: The marriage, in 1335, of Beatriz de Lauria to the second lord of Marchena was a fundamental event in the consolidation process of the Ponce de León lineage in Andalusia. At the same time, it completely altered Beatriz's own circumstances, not only due to the change of kingdom that her move from Valencia to Seville involved, but also due to the complex relations between Castile and Aragon during the central decades of the $14^{\text {th }}$ century. All this affected her aspirations to lordship in Valencia, hampered by the activities of her brothers Jaime and Pedro de Jérica. The fact that she outlived her husband by more than twenty years allows us to analyse her role in the Andalusian context, a little-known aspect, but one of great interest for the reign of Peter I of Castile, so adverse for the great Sevillian lineages.

Keywords: nobility; lineage; seigneurial system; Ponce de León; Guzmán; Jérica/Xèrica.

\section{SUMARIO}

1. Introducción: el contexto familiar.- 2. El matrimonio con Pedro Ponce de León.- 3. La viudedad en Andalucía.- 4. Retiro y muerte.- 5. Conclusión.-6. Bibliografía citada. 


\section{INTRODUCCIÓN: EL CONTEXTO FAMILIAR ${ }^{1}$}

Aunque la conquista de la Andalucía del Guadalquivir, a mediados del siglo XIII, ofreció a la nobleza castellano-leonesa un extenso marco espacial sobre el que poder actuar, la señorialización fue aquí un proceso tímido, inestable y periférico durante lo que restaba de la centuria ${ }^{2}$. Hay que esperar hasta finales del siglo XIII y principios del XIV para encontrar los orígenes de la alta nobleza andaluza, que surge como una nobleza escindida de linajes leoneses, trasplantada en el nuevo territorio y supeditada -por poco tiempo- a las ramas principales de las respectivas familias. Los ejemplos que proporcionan los linajes de Guzmán y Ponce de León resultan paradigmáticos, con un liderazgo temprano pero mantenido durante quinientos años. Alonso Pérez de Guzmán "el Bueno", primer señor de Sanlúcar de Barrameda (†1309), constituye el prototipo de gran noble andaluz: segundón de origen leonés, con una activa participación militar en la frontera, conexiones políticas internacionales y capacidad para reunir un notable patrimonio señorial geográficamente concentrado.

La posición que ocupaban estos nobles en sus linajes de origen, así como las propias necesidades de conformación como grupo diferenciado y anclado territorialmente a un nuevo solar de referencia motivaron que, en un primer momento, las estrategias matrimoniales se caracterizasen por su localismo, la radical endogamia y una cierta hipergamia en el plano económico que se traducía en dotes susceptibles de justificar por sí mismas nacientes estados señoriales. Guzmán el Bueno, por ejemplo, casó con María Alfonso Coronel, que residía en Sevilla y dispuso de una sustanciosa dote ${ }^{3}$. Fernán Pérez Ponce, el primer señor de Marchena, casó con una hija de Guzmán, mientras que el heredero de este lo hacía con una hermana de aquel ${ }^{4}$. Otra hija de Alonso Pérez de Guzmán casaría con Luis de la Cerda, que se convirtió así en señor de El Puerto de Santa María.

Ahora bien, observamos un cambio drástico en la política matrimonial de la segunda generación de señores de Sanlúcar de Barrameda o de

\footnotetext{
${ }^{1}$ Abreviaturas utilizadas: $\mathrm{ACA}=$ Archivo de la Corona de Aragón; $\mathrm{ADM}=$ Archivo Ducal de Medinaceli; AGFCMS = Archivo General de la Fundación Casa Medina Sidonia; AHNOB = Archivo Histórico de la Nobleza; BNE = Biblioteca Nacional de España; RAH = Real Academia de la Historia. Debo agradecer encarecidamente las facilidades ofrecidas por la Fundación Casa Ducal de Medinaceli y por su presidente, D. Juan Manuel Albendea Solís, para consultar la documentación de su Archivo durante la pandemia que cerró las instituciones culturales y de investigación en la primavera de 2020.

${ }^{2}$ Cabrera 1999, pp. 93-96.

${ }^{3}$ Ladero 2002; 2015, pp. 27-55.

${ }^{4}$ Carriazo 2002, pp. 44-50; 2007. Pedro Barrantes Maldonado, el más importante cronista de la casa de Medina Sidonia, afirmará a mediados del siglo XVI que la magnanimidad de Guzmán el Bueno con la dote de su hija fue tal, que por ella "tomó prinçipio la Casa que los Ponçe de León tienen en el Andaluzía” (Barrantes, Ilustraciones, p. 208).
} 
Marchena. Con las bases territoriales sólidamente establecidas y un sentido de grupo muy claro, los hijos de los fundadores de las ramas andaluzas de los Guzmán y los Ponce de León utilizaron el matrimonio como factor generador de prestigio, tanto frente a las ramas principales de sus respectivas familias como en su contexto geográfico más cercano, en el que necesitaban autoafirmarse como linajes preeminentes y diferenciados. Una vez que el hijo de Guzmán el Bueno enviudó de su primera esposa, la hermana del señor de Marchena, casó con Urraca Osorio, hija de Álvar Núñez Osorio, conde de Trastámara ${ }^{5}$. Más notorio, incluso, será el matrimonio del segundo señor de Marchena, Pedro Ponce de León, con Beatriz de Lauria y Jérica, nieta del infante Jaime de Jérica, al que Jaime I el Conquistador consideró hijo legítimo en su testamento. A Jaime le sucedió en el señorío de Jérica su hijo homónimo, casado con Beatriz de Lauria, la madre de nuestra Beatriz, hija de Roger de Lauria y señora de Cocentaina, en el reino de Valencia ${ }^{6}$. Un siglo antes que el segundo señor de Marchena, otro Pedro Ponce, su bisabuelo, había casado con una hija ilegítima de Alfonso IX de León, acontecimiento muchas veces recordado por la historiografía del linaje y que perpetuará su emblema heráldico ${ }^{7}$. El matrimonio de Pedro Ponce de León superaba con creces al de su antepasado, al tratarse de una descendencia legítima y de una monarquía extranjera.

Conocemos bien el entorno familiar de Beatriz de Lauria gracias a la tesis doctoral de Maria Mercè Costa i Paretas ${ }^{8}$. Los fondos del Archivo de la Corona de Aragón permiten analizarlo con bastante detalle, no solo por la propia conservación de los registros de cancillería, sino también por el grado de proximidad de la casa de Jérica a la monarquía catalano-aragonesa. Debo aclarar que prefiero la denominación de "Beatriz de Lauria" a la de "Beatriz de Jérica", pues fue la que usó ella misma con más frecuencia. Interesa, en este sentido, el testimonio de Pedro Garcés de Cariñena, cubiculario del papa Benedicto XIII que comenzó a redactar su Nobiliario de Aragón en el mismo siglo XIV y se refiere a Beatriz como Beatriz de Lauria, aclarando incluso que se llamaba como su madre?. La denominación "Beatriz de Lauria y Jérica" aporta una solución de consenso y tiene igualmente una larga tradición historiográfica.

${ }^{5}$ Ladero 2015, pp. 57-58.

${ }^{6}$ La donación de Cocentaina a Roger de Lauria data de 1291 (ADM, Cocentaina, leg. 1, n. ${ }^{\circ}$ 1; Paz 1915, pp. 333-334). Posteriormente pasará a su hija (ADM, Cocentaina, leg. 1, n. ${ }^{\circ} 2$ ).

7 Carriazo 2002, p. 35.

${ }^{8}$ Costa 1998. Además de un pormenorizado estudio sobre la evolución del linaje, ofrece una interesante colección diplomática.

${ }^{9}$ Garcés de Cariñena, Nobiliario. Una nota marginal conservada en el manuscrito de la obra que pasó por las manos de Zurita y las de Jerónimo Blancas advierte de que "dévese averiguar si doña Beatriz de Exérica, muger de don Pedro Ponce de León, fue hija o hermana de don Pedro de Exérica" (BNE, MSS/3327, f. 3r; RAH, Col. Salazar y Castro, C-37, signatura moderna: 9/260, f. 1v). Cf. Ubieto 1986, pp. 137-142; Domingo 2010, p. 114. 
Sabemos de la estrecha vinculación de Beatriz con su madre y hermana, de las complejas relaciones con sus hermanos varones, de los proyectos matrimoniales y de sus reiteradas reclamaciones. En cambio, sus años andaluces -casi cuatro décadas- han recibido muy poca atención. En principio, las disposiciones de sus progenitores debían haber garantizado a Beatriz una vida acorde con su procedencia. Su padre, Jaime, el segundo señor de Jérica, otorgó testamento el 16 de agosto de 1321 y murió antes de finalizar el año ${ }^{10}$. Dejaba como sucesor al primogénito, otro Jaime. En su última voluntad, el segundo señor de Jérica repartió cuanto poseía entre el heredero y sus hermanos Pedro y Alfonso. A las hijas, Beatriz y María, les dejaba 100.000 sueldos a cada una, que el primogénito habría de entregarles cuando se casasen. Si no tenían descendencia, les corresponderían solo 50.000 sueldos, y el resto de la cantidad retornaría a Jaime ${ }^{11}$. Además, debían recibir una parte, igual a la de sus hermanos, de los bienes muebles, vajilla, plata y joyas de la casa ${ }^{12}$. Según el fuero de Aragón, la viuda del segundo señor de Jérica, Beatriz de Lauria, disfrutaría mientras viviese de los bienes de su difunto esposo, sin posibilidad de enajenar patrimonio. Disponía además del señorío de Cocentaina, que había heredado de su padre.

No debemos obviar el ejemplo que para nuestra Beatriz constituyó su madre, a la que estuvo siempre muy unida. Tras la muerte del segundo señor de Jérica, su viuda se vio enfrentada a su propio hijo por el disfrute de la herencia ${ }^{13}$. Beatriz y María se mantuvieron siempre del lado de la madre. Es más, ellas mismas tuvieron que emprender acciones contra su hermano. En febrero de 1330, de manera conjunta, buscan la protección de Alfonso IV el Benigno y le piden que obligue a Jaime a pagarles la cantidad que se les debía de la herencia paterna, según la tasación establecida por sentencia real ${ }^{14}$. Pero el rey prefirió mantener sus buenas relaciones con el señor de Jérica y sugirió a su

${ }^{10}$ Costa 1998, p. 83.

${ }^{11}$ Ibidem, pp. 85-86.

12 Ibidem, p. 243.

${ }^{13}$ Ibidem, pp. 101-110. Como observa Costa i Paretas, "la figura de Beatriu de Lloria, que apareix d'una forma discreta en els documents de la seva joventut, va adquirint protagonisme arran de la mort del seu marit, Jaume (II) de Xèrica, fins a mostrarse amb tota la seva personalitat en els anys immediatament següents. El fet que Jaume l'hagués deixat senyora vitalícia de la casa i béns de Xèrica li donà una força que la portà, fins i tot, a un dur enfrontament amb el seu fill gran, el qual es considerava l'hereu de casa seva i amb aquest caràcter volia disposar de tot" (ibidem, p. 89). Andando el tiempo, su hija vivirá circunstancias análogas.

${ }^{14}$ El documento está fechado en Cocentaina. Nuestra protagonista se presenta como "Beatriz de Loria", usando el mismo nombre que su madre. Ambas hermanas se encomiendan al rey, de quien esperan "mas de bien e merçe que de todos los seynnores del mundo". Exponen al monarca que "no devedes consentir que nuestro hermano nos tuelga lo que nuestro padre nos lexo", toda vez que, "catada nuestra condicion, no es tanto lo que nos taxastes que aquello nuestro hermano nos deviesse contrastar" (ibidem, pp. 371-372, doc. 111). Con gran discreción, 
madre que levantara el embargo si aquel se comprometía a designar fiadores para pagar la deuda en un plazo breve. Jaime debía entregar 8.000 sueldos cada año para el mantenimiento de las hermanas. Aunque el joven señor de Jérica objetó que la sentencia era nula, el rey desestimó su queja. La madre reclamó la ejecución de dicha sentencia y Alfonso IV dio de plazo hasta enero de 1331. Pero tampoco entonces saldó Jaime la deuda con sus hermanas ${ }^{15}$. Una década después de la muerte de su padre, Beatriz seguía sin cobrar la cantidad que este le había legado en su testamento. Tampoco se le había entregado la parte correspondiente de los bienes muebles, vajilla y plata de la casa. Y siendo, posiblemente, la mayor de los hermanos, seguía sin casar.

En 1326 se habían iniciado las negociaciones para su matrimonio con el infante Ramón Berenguer. Dado que eran primos bastante próximos, el rey Jaime II tenía dudas sobre la posibilidad de realizar la unión. Para despejarlas, consultó la cuestión con el Papa ${ }^{16}$. Este no manifestó oposición alguna, por lo que se solicitó a la Santa Sede una dispensa de tercer grado de parentesco. El 11 de septiembre fue otorgada la dispensa, que llegó al infante ya en noviembre ${ }^{17}$. En el mismo mes de septiembre, sin dilación, se habían asentado las capitulaciones matrimoniales. Beatriz debía llevar 500.000 sueldos reales en ajuar. Se estipuló incluso la forma de pago, pero el matrimonio no llegó a realizarse. En julio de 1327 se rubricaba el compromiso entre el infante Ramón Berenguer y Blanca, la hija del príncipe Felipe de Tarento ${ }^{18}$. En 1333 apareció un nuevo pretendiente para Beatriz: Amalric, hijo del vizconde Eimeric de Narbona. Amalric se entrevistó con Alfonso IV en Tortosa y hablaron de la cuestión. El rey envió un mensajero para tratar el asunto tanto con el vizconde como con la madre de la joven ${ }^{19}$. Este proyecto matrimonial tampoco llegó a buen puerto, pero el tercer y definitivo pretendiente no tardó en aparecer.

\section{El MATRIMONiO CON PEDRO PONCE DE LeÓN}

A comienzos de 1334, doña Beatriz de Lauria envió a Munio López de Tauste, alcaide de Cocentaina y su hombre de confianza, para tratar con

dejan ver que la compensación establecida no era del todo satisfactoria para ellas, y que, en cualquier caso, solo la intervención real podía hacer justicia.

${ }^{15}$ Ibidem, pp. $244-245$ y p. 377 , doc. 124

${ }^{16}$ Ibidem, pp. 341-342, doc. 73.

${ }_{17} \mathrm{Al}$ mismo tiempo, "el papa escrivia al rei i li deia que vigilés que a la núvia no li passés res que la fes desagradable o que la inutilitzés per a tenir descendència, perquè li doldria que l'infant la tingués així por esposa" (ibidem, p. 243).

${ }_{18}$ Ibidem, p. 244.

${ }^{19}$ Ibidem, pp. 245 y 384-385, doc. 134. 
Alfonso IV el matrimonio de su hija con Pedro Ponce de León, segundo señor de Marchena. Parece que la propuesta había partido del propio Pedro ${ }^{20}$. Pero, ¿cómo sabía un noble sevillano de la existencia de Beatriz y de su disponibilidad para contraer matrimonio? Es preciso recordar que Jaime de Jérica, el hermano de Beatriz, había marchado en 1333 a Castilla para colaborar con Alfonso XI en la defensa de Gibraltar ${ }^{21}$. Este gesto cuadra bien con los deseos del señor de Jérica de combatir a los musulmanes, y fue acogido con satisfacción por el rey castellano, que lo agradeció a su homónimo aragonés ${ }^{22}$. Recordemos que ambos monarcas eran cuñados, pues Alfonso IV de Aragón había contraído segundas nupcias con Leonor de Castilla, hermana de Alfonso XI ${ }^{23}$. Nos consta que, cuando el rey castellano se dirigía hacia Gibraltar, un escudero de Jaime de Jérica se presentó ante él en la localidad cordobesa de Fuenteovejuna para pedirle que aguardase la venida de su señor. La urgencia de los acontecimientos desaconsejaba cualquier dilación, por lo que el rey respondió que ya se encontrarían en Sevilla. No hizo falta esperar hasta entonces, pues don Jaime dio alcance a la comitiva regia en Constantina, en la sierra norte sevillana $^{24}$. El 6 de junio de 1333, el señor de Jérica acompañó al monarca a su entrada en la ciudad ${ }^{25}$.

Las crónicas de Alfonso XI dejan constancia de la participación efectiva de Jaime de Jérica en los combates contra los musulmanes, que habían recuperado Gibraltar ${ }^{26}$. Allí murió, por ejemplo, el escudero que se entrevistó con Alfonso XI en Fuenteovejuna ${ }^{27}$. Las provisiones escaseaban y hacían falta más efectivos. Al parecer, Jaime de Jérica recurrió a algunas rentas que tenía en Valencia para colaborar en los gastos, e incluso envió un mensajero a pedir al rey de Aragón que mandase sus galeras. No fue posible, pues la flota se ocupaba por entonces de proteger a los comerciantes catalanes y valencianos

${ }^{20}$ Ibidem, p. 246.

${ }^{21}$ Ibidem, pp. 123-124 y 386-388, docs. 136-138. Sobre las actividades fronterizas del personaje, véase Cabezuelo 1997.

${ }_{22}$ Moxó 1982, p. 190, n. ${ }^{\circ} 101,104$. Cualquier apoyo era bienvenido, por lo que Alfonso XI obviaría fácilmente la estrecha amistad de Jaime de Jérica con don Juan Manuel, que explica incluso su influencia en la redacción de El conde Lucanor (Taylor 1986).

${ }^{23}$ Jaime y Pedro de Jérica estarán presentes al año siguiente en la entrevista de Alfonso XI con su hermana Leonor en Ateca (Moxó 1982, p. 193, n. ${ }^{\circ}$ 126; Costa 1998, p. 126). La Crónica de Alfonso XI comenta que el señor de Jérica y su hermano "servían et ayudaban a la reyna, hermana del rey, et a los infantes sus fijos en quanto podían" y se comprometieron a defender sus intereses ante la inminente muerte de Pedro IV, incluso "faciendo guerra en el regno de Aragón", si era preciso (Crónica, p. 265).

${ }^{24}$ Tanto la Crónica como la Gran crónica de Alfonso XI recogen puntualmente este encuentro (Crónica, p. 246; Gran Crónica de Alfonso XI, pp. 35-36).

${ }^{25}$ Costa 1998, p. 124.

${ }^{26}$ Crónica, pp. 251-252; Gran Crónica, pp. 50-51.

${ }^{27}$ Crónica, p. 253; Gran Crónica, pp. 54-55. 
del hostigamiento genovés. En cualquier caso, Jaime de Jérica se convirtió en informador privilegiado para el rey de Aragón, a quien hizo llegar, durante todo el verano, noticias sobre el cerco de Gibraltar. Entrado ya el otoño, el monarca lo llamó para encargarle otra misión ${ }^{28}$.

Durante los meses que Jaime de Jérica permaneció en Andalucía, tuvo forzosamente que entrar en contacto con Pedro Ponce de León, segundo señor de Marchena, bien asentado en Sevilla y muy bien relacionado. A Pedro Ponce de León le interesaba enormemente un matrimonio semejante, que le permitiría despuntar entre el resto de linajes de la región y le conferiría mayor protagonismo en la corte de Alfonso XI. Desde la perspectiva de los Jérica, los beneficios derivados de aquel posible enlace eran más modestos, pero cabe especular sobre la conveniencia para Jaime de alejar a su hermana del núcleo familiar y debilitar así el pequeño bando doméstico que formaba junto con su madre y su otra hermana. En cualquier caso, la ascendencia del señor de Marchena constituía una excelente carta de presentación. Su abuelo, Fernán Pérez Ponce, fue adelantado mayor de la frontera y ayo de Fernando IV; su tío abuelo, Ruy Pérez Ponce, maestre de Calatrava; y su tío, Pedro Ponce de León, mayordomo del rey y, de nuevo, adelantado mayor de la frontera ${ }^{29}$. Además, era nieto de Guzmán el Bueno, lo que lo vinculaba al influyente grupo de los Guzmán y los Coronel $^{30}$. En 1332, había sido armado caballero - como otros vástagos de grandes familias castellanas- durante la ceremonia de coronación de Alfonso XI en Burgos ${ }^{31}$. En los años siguientes, la frontera le brindará ocasiones para demostrar su capacidad militar y el compromiso de los Ponce andaluces con la corona ${ }^{32}$.

El monarca aragonés estaba de acuerdo con el enlace y tan solo incluyó algunos aspectos concretos en el texto de las capitulaciones matrimoniales. Aconsejó además a la futura suegra que enviase un caballero a Sevilla para conocer las intenciones del pretendiente, antes de trasladar el asunto al rey de Castilla ${ }^{33}$. Sin embargo, mientras se realizaban los preparativos nupciales, el 3 de junio de 1334, tuvo lugar la muerte de doña Beatriz de Lauria. Dos días después, el 5 de junio, sus hijas, Beatriz y María, informan del fallecimiento a Alfonso IV, a quien se encomiendan recordándole los vínculos de

${ }^{28}$ Costa 1998, p. 124.

${ }^{29}$ Carriazo 2002, pp. 41-42; Vázquez 2006, pp. 164-176, 203-210.

${ }^{30}$ En abril de 1320, por ejemplo, Pedro Ponce de León figura junto con su abuela, María Alfonso Coronel, en la carta de hermandad firmada con los concejos de Sevilla, Córdoba, Carmona, Écija y Niebla para la defensa de la frontera andaluza (García 1985, p. 370).

${ }^{31}$ Crónica, pp. 235-237.

${ }^{32}$ Carriazo 2002, pp. 59-60.

${ }^{33}$ Costa 1998, pp. 246, 393-394, doc. 142. 
parentesco existentes y los servicios de su difunto padre ${ }^{34}$. Buscaban también su protección, ante la incertidumbre en que las sumía la pérdida de tan buena madre $e^{35}$. Doña Beatriz había hecho testamento el 15 de mayo ${ }^{36}$. Puesto que su hijo Jaime no tenía sucesión y que el segundo, Pedro, heredaría la baronía de Jérica, Beatriz designó como sucesor en la de Cocentaina al tercero de los hijos, Alfonso, que sumó a su nombre el del almirante y pasó a llamarse Alfonso Roger de Lauria y Jérica. Si este moría sin descendencia, los bienes pasarían a su hermano Pedro. Y si este tampoco dejaba herederos, la herencia recaería en su hermana Beatriz, que tendría que llevar obligatoriamente el apellido de Lauria en honor a su abuelo ${ }^{37}$.

Pese a la muerte de su madre, las negociaciones para el matrimonio de Beatriz siguieron su curso. El mismo 5 de junio en que fue informado del fallecimiento, el rey ordenó a Jaime de Jérica que continuase con los preparativos y enviase a Castilla un caballero para tratar el asunto con el señor de Marchena ${ }^{38}$. Un interesante documento fechado una semana después nos permite leer entre líneas. Alfonso IV escribe a Beatriz informándole de que ha hablado sobre su matrimonio con sus hermanos Jaime y Pedro. Le comunica que ve con buenos ojos la unión, dada la nobleza del dicho Pero Ponç, y ruega a la joven que consienta en casarse. Como apostilla final, le asegura que si supiese que podía casar mejor con cualquier otro, no dudaría en velar por su bien y su honra, dado el parentesco que les unía ${ }^{39}$. El rey se anticipa a los posibles reparos de Beatriz, que tal vez no considerase aquel enlace adecuado a su rango, pero lo cierto es que accedió.

El 26 de junio, el soberano aragonés comunicó a Alfonso XI de Castilla el consentimiento de Beatriz y sus hermanos, justificando el retraso en la respuesta por la enfermedad y muerte de la madre. En el documento

34 Ibidem, p. 95. Justo un mes después, los testamentarios de Beatriz de Lauria tomarán posesión de los lugares de Planes y Almudaina (ADM, Cocentaina, leg. 4, n. ${ }^{\circ} 29$ ).

35 Costa 1998, p. 394, doc. 144. En el documento, Beatriz de Lauria es solo la madre. Las hijas se presentan como "dona Beatriç e Maria Alvareç".

${ }^{36}$ Con codicilo el 16 de mayo (ADM, Cocentaina, leg. 9, n. ${ }^{\circ} 43$ ).

37 Costa 1998, p. 95. Subrayó también esta vinculación entre apellido y señorío Luis Fullana en su trabajo sobre la casa de Lauria (1923, pp. 129, 150).

38 Costa 1998, p. 246. Costa i Paretas consigna la existencia de la carta en su apéndice documental (ibidem, p. 395, doc. 145), aunque no la transcribe. El monarca recuerda aquí a Jaime de Jérica que su madre, antes de morir, "auia acordat" enviar un caballero a Castilla "per certificarse d'algunes coses que eren necessaries en lo feyt del matrimoni del noble don Pero Ponç e de la noble dona Beatriç", pero que dicho matrimonio ya está asegurado y lo da "per bo e per honrat", por lo que le encarga que "vos donets bon acabament" (ACA, Cancillería, Registros, n. ${ }^{\circ}$ 536, f. 8r).

39 Literalmente, el rey dice a Beatriz: "creer podedes que si nos sabiessemos que millor podessedes casar con otri, nos toda vegada catariamos honra e bien vuestro, esguardado lo parentesco que con nos avedes" (Costa 1998, p. 395, doc. 146). 
alaba específicamente la labor realizada por Roy Ferrandez de Reureda e Alver Garceç de Illar, cavelleros, vuestros vassallos, en raçon del matrimonio de don Pero Ponç e de donya Beatriç ${ }^{40}$. El primero es Ruy Fernández de Robreda, personaje próximo a los Ponce de León ${ }^{41}$. Respecto al segundo, podemos identificarlo con Álvar García de Illas, que prestará distintos servicios al rey castellano $^{42}$. El aragonés considera que:

estos cavelleros fizieron bien e cuardament con grant diligencia en este tractamiento canto podieron, pero, puesto que dona Beatriç de Loria, su madre, fue enferme, de la qual enfermedad morio, non pudieron ten ayna avençar, ante ovieron fasta agora afincar ${ }^{43}$.

El monarca escribió también, en el mismo sentido, a Pedro Ponce de León ${ }^{44}$. Seis meses más tarde, a finales de enero de 1335, Alfonso IV informaba al noble don Pero Ponç que el matrimonio había sido firmado en la ciudad de Valencia, estando presente Beatriz y sus hermanos Jaime y Pedro. Los caballeros enviados por Pedro Ponce de León actuaban en su nombre. El rey añade que, por honrar a los contrayentes, había acordado con los hermanos de la novia que casedes en nuestra casa. Eso sí, fija un plazo para celebrar la boda, pues tan solo permanecería en Valencia hasta la Pascua de Resurrección. El documento contiene también instrucciones sobre ciertos documentos que debían aportar tanto el novio como Alfonso XI de Castilla. Pero lo que de verdad importa al

${ }^{40}$ Ibidem, p. 396, doc. 147.

${ }^{41}$ Debe tratarse del mismo Ruy Fernández de Robreda, vecino de Niebla, que recibió la aldea de Facanías (antecedente de la localidad onubense de Valverde del Camino) por concesión de Fernando IV; dominio que no llegó a hacer efectivo y al que renunció, en 1315, por mediación de Fernán Pérez Ponce (Ladero 1992, pp. 33-34; Anasagasti y Rodríguez 2006, pp. 326-327, doc. 66). Aunque se ha identificado al dicho Fernán Pérez Ponce con el adelantado mayor, dado que este murió en 1291 y teniendo en cuenta la ubicación geográfica del frustrado señorío, debe tratarse más bien del primer señor de Marchena, padre de Pedro Ponce de León. De ser así, la relación de Fernández de Robreda con la casa de Marchena vendría, al menos, de veinte años atrás.

${ }^{42}$ En marzo de 1336, Alfonso XI concederá a Álvar García de Illas, su alcalde y vasallo de su hijo Pedro, una heredad en término de Los Molares, entre Utrera y Morón de la Frontera, con autorización para edificar una fortificación que se conocerá como la torre del Bao y facultad para repoblar el lugar. En 1344, el rey le confirmará estos privilegios, siendo alcalde mayor de la recién conquistada Algeciras (Ladero 1984, p. 491; García 1988, p. 150; González 1993, pp. 82-83, 182-185). En 1342, García de Illas había acompañado a Alfonso Fernández Coronel en su embajada a Aviñón, ante Clemente VI (Serrano 1915, p. 5, n. 5; Torremocha 1994, p. 62, n. 67; Trenchs 1980, pp. 14, 18). Se ha destacado la formación de Álvar García (Villarroel 2018, p. 128), así como la significación de la embajada en el contexto de las complicadas relaciones entre Alfonso XI y el papado (Arias 2012, pp. 191-197). Sobre el personaje, véase Carriazo 2021.

${ }^{43}$ Costa 1998, p. 396, doc. 147.

${ }^{44}$ Como observa Costa i Paretas, "així com el consentiment fou ràpid, l'acord final i les noces tardaren una mica més. Uns nuncis de Ponce esperaren molt de temps a la cort per tal que Jaume [de Jérica] hi acompanyés Beatriu a signar el compromís" (ibidem, p. 246). 
aragonés era que Pedro Ponce de León estuviera en Valencia para recebir benedicción antes de la Pascua; plazo que no debía ser modificado en ninguna manera ${ }^{45}$. Una boda en palacio y ante el rey debía satisfacer tanto a Beatriz como a sus familiares y, por supuesto, al señor de Marchena.

A finales de febrero, Pedro Ponce de León designa como su procurador para la boda a Ruy Fernández de Robreda, que se desplazó a Valencia con plenos poderes para que podades otorgar a mí el dicto don Pero Ponç por esposo i por marido de la dicta dona Beatriç (...), e otrossí que podades recebir por mí i para mí i en mi nombre por esposa i por muger a la dicta dona Beatriç ${ }^{46}$. Lo facultaba además para que podades dar i prometer i obligar de m.is bienes a la dicta dona Beatriç por dote i por arras lo que uos abinierdes (...), lo que yo mismo faría estando presente, a cuyo cumplimiento, dice Pedro Ponce de León, obligo todos míos bienes ${ }^{47}$.

Jaime y Pedro de Jérica actuaban como procuradores de su hermana y, según parece, en la negociación estuvo presente la reina Leonor. Sabemos que Pedro Ponce de León entrega como dote y arras de Beatriz, según fuero de Aragón, el lugar de Marchena y la mitad de Rodelga y de Quintanilla, dos lugares leoneses, en término de Benavente, recibidos en herencia de su padre $^{48}$. En representación del novio, confirma el acuerdo su hermano, Fernán Pérez Ponce ${ }^{49}$. Entre los testigos figuran el obispo de Burgos, García de Torres Sotoscueva, y el alcaide de Cocentaina, Munio López de Tauste, testamentario de la madre de Beatriz. Acordadas las capitulaciones, se estableció un plazo hasta la fiesta de San Juan Bautista para hacerlas efectivas. Sin embargo, en octubre de 1335, Fernán Pérez Ponce, el hermano de Pedro, tiene que confir-

${ }^{45}$ Ibidem, p. 399, doc. 151. La urgencia del rey parece deberse a que no pensaba permanecer en Valencia más tiempo, "perquè allà, a l'estiu, feia molta calor. Per això demanà a Alfons XI que fes venir Ponce, de manera que no l'hagués d'esperar més del compte; i li enviava una nota, a manera d'esborrany, per tal que el rei castellà fes una lletra a Beatriu que permetés de realitzar el matrimoni. Igualment donà als nuncis de Ponce una sèrie de documents que aquest havia de despatxar amb Alfons XI per formalitzar-ho tot. A Ponce li deia que vingués per Pasqua per casar-se, i que procurés que el rei de Castella no canviés res del que deia la nota que ell li havia enviat". Como apunta Costa, "no sembla que el desig del rei es complís a la perfecció, perquè el 23 de maig, com que s'apropava, deia, el casament de Beatriu, volia que els marmessors de la seva mare li donessin el llegat d'aquesta, consistent en vestits, alguna joia i altres coses, o el seu valor en diner" (ibidem, pp. 246-247).

${ }^{46}$ El documento se refiere a Fernández de Robreda como "cauallero procurador" de Pedro Ponce de León y "vassallo de mío senyor el rey don Alfonso" (ADM, Cocentaina, leg. 9, n. $\left.{ }^{\circ} 19\right)$.

${ }^{47}$ ADM, Cocentaina, leg. 9, n. ${ }^{\circ}$ 19. Aunque Pedro Ponce de León se presenta como vecino de Sevilla, el documento está firmado en Marchena, el 26 de febrero, suponemos, de 1335, pues uno de los importantes rotos de la pieza impide completar la lectura. Paz y Melia dio noticia de la existencia de estas capitulaciones (Paz 1915, p. 336).

${ }^{48}$ ADM, Cocentaina, leg. 9, n. ${ }^{\circ}$ 19; AFCMS, leg. 917, primer documento.

${ }^{49}$ Fullana lo confundió con el padre de ambos, del mismo nombre (1923, p. 157). 
mar que los lugares señalados serán entregados de manera efectiva a Beatriz, que en todo momento figura como Beatriç de Loria ${ }^{50}$.

La actuación de Fernán Pérez Ponce de León en este proceso resulta interesante. El documento especifica que se trata del hermano de Pedro Ponce de León, lo que lo identifica con el futuro maestre de Alcántara, que ostentará el cargo entre 1346 y $1355^{51}$. Rades y Andrada comenta en su Crónica de las tres órdenes que este maestre, antes y después de su elección, siruió al rey don Alonso en muchas guerras y batallas contra moros, como la batalla del río Palmones (1342) o la toma de Algeciras (1344) ${ }^{52}$. Poco antes, lo encontramos combatiendo a los meriníes como frontero en $\operatorname{Arcos}^{53}$. Debieron ser estos servicios, así como su ascendencia, los que le permitieron alcanzar la dignidad maestral ${ }^{54}$. Ahora bien, en 1335 solo era el hermano del señor de Marchena, y como tal se presenta y actúa. En las negociaciones matrimoniales de Valencia, además del matrimonio de Pedro Ponce de León, estaba en juego la consolidación y proyección de la rama andaluza de su linaje, en el contexto local y regional, pero también frente a los parientes leoneses. Es muy elocuente, en este sentido, la prelación de Ruy Pérez Ponce, cabeza de estos últimos, respecto a su primo andaluz, en la ceremonia de la coronación de Alfonso XI de $1332^{55}$. Siendo ambos ricos hombres, Ruy desfiló más próximo al rey y armó a diez caballeros. Pedro armó a cinco y aparece en el cortejo junto a su primo pero en segundo lugar ${ }^{56}$.

Pedro Ponce de León poseía, además, un conjunto notable de territorios señoriales repartidos por el reino de Sevilla. Su padre había recibido del rey, en 1304, Bornos y otras aldeas en término de Arcos de la Frontera ${ }^{57}$. Su madre, Isabel de Guzmán, había llevado en dote, según Barrantes Maldonado, Rota, Chipiona, la mitad de Ayamonte y un empeño sobre Marchena que permitió posteriormente alcanzar el señorío completo sobre la población ${ }^{58}$. Más tarde, Isabel recibiría de su madre la mitad de Bollullos y Montañina, así como las aceñas que esta poseía en el Guadalete, en término de Jerez de la Frontera. Ahora bien, en la década de 1330 este patrimonio señorial no creció de manera significativa. En 1337 Alfonso XI concedió a Pedro Ponce

${ }^{50}$ ADM, Cocentaina, leg. 9, n. ${ }^{\circ} 19$.

${ }^{51}$ Ayala 2003, p. 851.

52 Rades 1572, ff. 25v-27r. Sobre el cronista, véase el documentado estudio de Gómez Vozmediano (2016).

${ }^{53}$ Crónica, p. 300.

${ }_{54}$ Novoa 2003, p. 1078.

${ }_{55}$ Carriazo 2002, pp. 57-60.

${ }^{56}$ Crónica, pp. 235-237.

57 Carriazo 2002, p. 45.

${ }^{58}$ Barrantes, Ilustraciones, p. 207. 
de León los lugares extremeños de Oliva de la Frontera y Valencia del Mombuey, pequeños núcleos de población en la raya extremeña con Portugal. Tanto su carácter fronterizo y potencialmente conflictivo como lo alejado del resto de señoríos del linaje los hicieron poco atractivos para la casa, que se deshará de ellos en $1402^{59}$.

En Valencia, las perspectivas no eran muy halagüeñas para Beatriz. Seis meses después que su madre, a comienzos de 1335, moría su hermano Jaime. Rondaba los treinta años de edad y no dejaba descendencia, por lo que Pedro, como estaba previsto, se convirtió en nuevo señor de Jérica ${ }^{60}$. En 1336 muere Alfonso IV el Benigno, dando paso al reinado de Pedro IV el Ceremonioso, que se extendió durante más de medio siglo. Con el cambio de monarca, la casa de Jérica vivió momentos muy difíciles, por el apoyo prestadoaLeonordeCastilla, lamadrastradel rey, que fueauxiliada también por su hermano Alfonso $\mathrm{XI}^{61}$. En 1338 volvió la calma entre los reinos y los parientes ${ }^{62}$. La casualidad quiso que el infante Ramón Berenguer-que pudo haber sido esposo de Beatriz- enviudase en 1337 y se casara dos años más tarde, también en Valencia, con su hermana menor, María Álvarez ${ }^{63}$. Por lo que respecta a Beatriz, desde antes de su boda se había solicitado que los albaceas de su madre le entregasen los bienes muebles que le correspondían, valorados en 21.580 sueldos. Sin embargo, en 1340 todavía no había sido satisfecha esta deuda ${ }^{64}$. Además, los plazos impuestos por el rey a Pedro de Jérica para la entrega de la herencia paterna fueron sucesivamente prorrogados. Beatriz tuvo que recurrir al propio Alfonso XI para que intercediera ante Pedro IV. Teniendo en cuenta los acontecimientos precedentes, no es extraño que las gestiones resultaran infructuosas. Tampoco sorprende que el propio rey de Castilla tomara cartas en el asunto, pues el marido de Beatriz se había convertido ya en una pieza importante para la defensa de la frontera andaluza ${ }^{65}$.

59 Ladero 1973, pp. 19-20.

${ }^{60}$ Costa 1998, p. 148.

${ }^{61}$ Ibidem, pp. 150-164.

${ }^{62}$ Como observa Costa i Paretas, "després de la guerra, la situació econòmica de Pere de Xèrica no era gens florida", no obstante, gracias a la prórroga de sus deudas "podria pagar a la seva germana Beatriu els $25.000 \mathrm{~s}$. reals que se li devien encara del llegat patern" (ibidem, p. 149). Ahora bien, que pudiera hacerlo no implica que estuviese dispuesto a saldar la deuda.

${ }^{63}$ Ibidem, p. 252.

${ }^{64}$ El 11 de octubre de 1340, el monarca ordena a los ejecutores testamentarios de la difunta Beatriz de Lauria que entreguen a su hija, "consortis nobilis Petri Poncii, domini de Marchena", el legado materno o la cantidad en que fue tasado (ibidem, pp. 439-440, doc. 202).

${ }^{65}$ La participación constante de la nobleza de la región en la guerra contra los musulmanes no derivaba solo de su mayor proximidad al escenario bélico, sino que constituía una contrapartida inherente a la recepción y posesión de sus señoríos (Arias 2012, p. 129). 
Pedro Ponce de León participó activamente en las campañas contra portugueses y meriníes ${ }^{66}$. También tomó parte en la batalla de El Salado (1340) y en la conquista y defensa de Algeciras (1344). Además, su hermano Fernán alcanzó en 1346 el maestrazgo de la orden militar de Alcántara. El premio a los servicios prestados no se demoró. En 1342, Alfonso XI concedió al señor de Marchena la población de Mairena del Alcor, segregándola del término municipal de Carmona ${ }^{67}$. En 1349, Pedro Ponce de León compra Bailén, aprovechando las necesidades financieras del rey para el cerco de Gibraltar ${ }^{68}$. Las gestiones del monarca castellano ante el aragonés en torno a la herencia de Beatriz de Lauria eran una deferencia más hacia el linaje de los Ponce de León.

Al parecer, María Álvarez, la hermana de Beatriz, ya había cobrado su parte. La señora de Marchena, en cambio, veía desvanecerse sus derechos. El 29 de marzo de 1346, desde Alcalá de Guadaíra, Alfonso XI transmite una vez más a Pedro IV las quejas de Beatriz ante la actitud de sus hermanos y de los albaceas de su madre ${ }^{69}$. El 1 de mayo es la propia Beatriz la que se dirige al monarca aragonés, pues onse anyos a que so en esta tierra después que casé e non puedo cobrar dellos ninguna cosa, aunque se lo había pedido por muchas veses. Explica seguidamente al rey que no solicitó antes su intervención pensando que me darien lo mío, pues tenía en su poder los documentos que respaldaban sus derechos. Pero, porque veo la grand desmesura que fasen contra mí en me non dar lo mio, ha decidido solicitar la intervención regia, e que les mandedes que me den todo lo mío. Beatriz explica que su hermano Pedro todavía le adeudaba veynte e çinco mille barciloneses que me fueron por pagar de çient mille barçiloneses que mi padre me dexó en su testamento que me diesen para mi casamiento. Aunque puso comigo penas e juro que me los pagarie fasta un anyo, lamenta que a onse anyos que case e non los puedo cobrar d·el. Además, su hermano Alfonso también le debe 200.000 sueldos barceloneses del testamento materno, razón por la cual tengo en penyos poderosament a Planas e al Almodayna con todas sus rentas e sus derechos fasta que me los quite, e fisieron-me por estos logares pleito e omenaje e estan por $m i^{70}$. Significativamente, al narrar el enfrentamiento de Pedro el Ceremonioso

\footnotetext{
${ }^{66}$ Carriazo 2002, pp. 59-60. Al dar cuenta de las talas de 1339 en Ronda, Archidona y Antequera, Jerónimo Zurita incluye, entre la "gente principal" que acompañó a Alfonso XI de Castilla, a "don Pero Ponce de León, señor de Marchena, que casó con doña Beatriz de Lauria de Ejérica, hermana de don Pedro de Ejérica" (Zurita, Anales, vol. III, p. 481).

${ }^{67}$ AHNOB, Osuna, C. 166, D. 1-5.

${ }^{68}$ AHNOB, Osuna, C. 183, D. 9; AHNOB, Osuna, C. 148, D. 1-16. García Fernández estima que, a la muerte de Alfonso XI, el señorío de los Ponce de León abarcaba 911,6 kilómetros cuadrados, es decir, un $2,9 \%$ del reino de Sevilla (1989, p. 182).

${ }^{69}$ Moxó 1988, p. 285, doc. 27.

${ }^{70}$ Costa 1998, pp. 446-447, doc. 214.
} 
con la Unión de Valencia, Zurita comenta que los valencianos combatieron el lugar y castillo de Planas, que era de doña Beatriz de Ejérica, mujer de don Pedro Ponce de León, señor de Marchena ${ }^{71}$.

Ahora bien, las rentas de Almudaina y Planes debían llegar a Beatriz muy mermadas y con dificultad, tanto por la lejanía geográfica como por la presión ejercida por su hermano ${ }^{72}$. En este sentido, denuncia que estas rentas e estos derechos e yo muy mal, que con las amenaças que lo que el fase non cobro sinon muy poco e a grrand menoscabo, que todo se pierde e non he ende pro. Después de muchos meses reclamando el pago de la deuda o que me dexase estos lugares, Beatriz asegura que Alfonso non lo quiere faser e dise que los tenga e que reçiba las rentas d ellos fasta que sean quitos. El cinismo de su hermano resulta notorio, por lo que expone al rey que en esta manera nunca yo podria ser pagada si vos non mandades que me pague o me dexe estos logares por el debdo que me deve $e^{73}$. A todo lo anterior hay que añadir los 21.500 sueldos en compensación por los bienes muebles que le correspondían por el testamento materno, que tampoco había recibido aún ${ }^{74}$. Y lo peor era el agravio comparativo existente con su hermana María, que es pagada de todo lo suyo e yo non, habiendo casado antes Beatriz.

Al pedir la intervención del rey, insiste en que, aunque don Pero Ponse e yo moramos aca en esta tierra tan luene, çierto sed que somos a vuestro serviçio en cualquier cosa que vos mandaredes e vuestro serviçio sea. Además, alude a las cartas enviadas por Alfonso XI de Castilla sobre el mismo asunto. No era la primera vez que el castellano reclamaba aquellos dineros en nombre de Beatriz, pero nunca había obtenido el resultado deseado ${ }^{75}$. Al término del documento, Beatriz reitera su súplica: senyor, sea vuestra merçed, pues yo so la mayor e casé primero e deviera ser pagada primero, que me querades faser derecho e non querades mi pecado, e fased me pagar lo mío ${ }^{76}$. Interesa observar que, al dirigirse al rey, se presenta como Beatris de Xerica, buscando tal vez distinguirse de su madre, Beatriz de Lauria, al tiempo que subrayaba su pertenencia a la familia.

En 1352 murió Pedro Ponce de León. En diciembre de 1354, Alfonso Roger, el hermano de Beatriz y señor de Cocentaina ${ }^{77}$. De inmediato, Beatriz

${ }^{71}$ Zurita, Anales, vol. IV, pp. 160-161.

${ }^{72}$ Costa 1998, p. 248.

73 Ibidem, p. 447, doc. 214.

${ }^{74}$ Beatriz especifica que se los deben "Jaymes Castellan e miçer Guillen Jafar e Munio Lopes", por "compusiçion que yo fis con ellos por ropas e aliferias que mi madre me dexo en su testamento" (ibidem).

${ }^{75}$ Ibidem, p. 248; Moxó 1986, p. 703, n. 22.

${ }^{76}$ Costa 1998, p. 447, doc. 214. Opto por la lectura "primero" en vez de "primo".

77 ADM, Cocentaina, leg. 3, n. ${ }^{\circ}$. Hasta ahora sabíamos que había muerto antes del 7 de enero de 1355 (Costa 1998, p. 238). 
reivindicó sus derechos sucesorios en virtud del testamento de su madre. Pero fue Pedro, el único varón superviviente, quien asumió el control del territorio con la connivencia del rey. No en vano, Pedro IV tenía que demostrar su gratitud hacia el señor de Jérica por participar en la expedición real a Cerdeña ${ }^{78}$.

\section{LA VIUDEDAD EN ANDALUCÍA}

La viudedad y la distancia geográfica no supusieron para Beatriz una mengua en el ánimo para encarar circunstancias adversas. En julio de 1355 llegó a Cocentaina su procurador y hombre de confianza, Alfonso Fernández de Onís, para reclamar el señorío ${ }^{79}$. El procurador se presenta en la población, en la puerta del alberch del jurado Jaime de Calatayud, ante este y ante Juan Martínez, lugarteniente del justicia del lugar. En nombre de la molt noble dona Beatriz de Loria, senyora de Marchena, procedió a dar lectura al documento enviado por su señora, en el que se recuerda cómo su madre dejó establecido en su testamento que lo dit loch et castell de Cocentayna e lo castell de Penella, junto con sus alquerías, serían para Beatriz si sus hermanos varones morían sin descendencia legítima. Aunque el lugarteniente Martínez se ausentó desde el primer momento, el procurador de Beatriz exigió que el alcaide López de Tauste hiciese entrega del castillo y prestase homenaje, y que se entregasen igualmente a su señora todas las rentas y derechos correspondientes al señorío desde el día que falleció Alfonso Roger de Lauria. Lejos de conseguir su propósito, cuando Fernández de Onís llegó a la puerta de la fortaleza, fue recibido por multitut de gents armades que le increparon con moltes e diuerses paraules injurioses y le conminaron, $a b$ gran força e ab armes, a marcharse fora de la villa ${ }^{80}$.

En 1356 estalló la "guerra de los dos Pedros" entre Castilla y Aragón. Desde este momento todas las gestiones de Beatriz estaban condenadas al fracaso. Puesto que residía en territorio enemigo, sus bienes fueron incautados como botín de guerra y sus vasallos liberados de toda obligación de fidelidad hacia ella. Detrás de todo aquello podemos suponer que estaba la mano de su hermano, Pedro de Jérica. Resulta sintomático que este solicitara al rey de Aragón que no entregase a nadie los bienes que habían pertenecido a Beatriz. En enero de 1357, alentado por sus consejeros, Pedro IV ordenó la ocupación

${ }^{78}$ Ibidem, pp. 496-498, docs. 275-280, y p. 500, doc. 287; ADM, Cocentaina, leg. 1, n. ${ }^{\circ} 3$.

79 ADM, Cocentaina, leg. 3, n. ${ }^{\circ}$ 1. Alfonso Fernández de Onís debe ser familiar de Ruy Fernández de Onís, uno de los cinco individuos que fueron armados caballeros por Pedro Ponce de León durante los actos de la coronación de Alfonso XI en Burgos en el verano de 1332 (Crónica, p. 237).

${ }^{80}$ ADM, Cocentaina, leg. 3, n. ${ }^{\circ} 1$. 
de aquellos señoríos y amenazó a sus vasallos con que serían considerados enemigos si no le prestaban homenaje ${ }^{81}$. En febrero, el castillo de Planes recibía a un nuevo alcaide puesto por el rey ${ }^{82}$. Aunque en la tregua de mayo de 1357 se dispuso la restitución a Beatriz de todos los bienes confiscados, no llegó a hacerse efectiva ${ }^{83}$. No obstante, Beatriz sí debía considerar posible la recuperación de Cocentaina y Penella, lo que justifica que el 10 de marzo de 1359 traspasase sus derechos hereditarios sobre estos lugares al segundo de sus hijos, llamado Pedro, como el padre ${ }^{84}$. Una vez más, se presenta como Beatriz de Loria, mujer del difunto Pedro Ponce de León, e hija legítima de sus progenitores. El documento está fechado en Marchena. Beatriz hace donación a su hijo, que se encuentra presente, de

toda la mi parte e derecho (...) que yo o otri por mí he e me perteneçe de hauer en qualquier manera que sea en la villa de Cocentayna e Penella, que son en el regno de Valencia, con todos sus términos, aldeas e alquerías, e con todos los derechos e rentas e fruytos e esquilmos que de los dichos lugares e términos se han cogido e recaudado desdel día que finó don Alfonso Rogel de Loria, mi hermano, que Dios perdone, fasta el día de hoy que esta carta es fecha, e de oy adelante para siempre jamás. E todo esto que sobredicho es vos do bien e complidamente, segunt que lo yo he e me perteneçe de heuer e de heredar por herencia de la dicha dona Beatriz mi madre, e segunt que ella me lo mandó por su testamento que ella fizo e otorgó antes que finasse. E todo esto que sobredicho es vos do (...), por quanto sodes mi fijo e recibo de bos muchas honras, tantas e tales de que me otorgo e tengo por muy bien pagada e entregada a toda la mi boluntat ${ }^{85}$.

Justifica además la donación porque el primogénito, Juan, heredó la casa de Marxena. A Pedro le pone dos condiciones: que cuando reciba de manera efectiva dichos lugares entregue diez mil maravedíes a cada uno de sus hermanos, Juan y María, y que tomedes la boz e las armas de Loria, es decir,

${ }^{81}$ El rey se dirige a las villas, fortalezas y lugares "que fuerunt Beatricis, uxoris Petri Poncii de Leon, cuius erat locus de Marchena", con lo que, indirectamente, reconoce la posesión hasta ese momento. Define a Beatriz como "nostra naturalis", aunque, "ad regnum Castelle dudum per matrimonium factum cum Petro Poncii domicilium suum transtulit et illud ad huc de facto detinet, in eodem remanendo in dicione et subieccione regis Castelle, hostis nostri, propter quod castellana debet merito reputari" (Costa 1998, pp. 504-505, doc. 292).

${ }^{82}$ Ibidem, p. 248.

${ }^{83}$ Ibidem, p. 219.

${ }^{84}$ ADM, Cocentaina, leg. 1, n. ${ }^{\circ}$ 9. Dio noticia de esta donación Paz y Melia en su selección de documentos del Archivo Ducal de Medinaceli, aunque la fecha erróneamente en 1397, al no realizar la necesaria conversión (1915, p. 335).

${ }^{85}$ ADM, Cocentaina, leg. $1, \mathrm{n}^{\mathrm{o}} 9$. 
el apellido y el emblema heráldico ${ }^{86}$. En cualquier caso, las circunstancias eran adversas. En abril de 1360, Pedro de Jérica es nombrado por el rey aragonés capitán general del reino de Valencia para la guerra con Castilla, Portugal y Granada $^{87}$. En mayo de 1361 se firmó la paz entre los reinos. Los procuradores de Pedro IV de Aragón consideraban que las poblaciones de Planes y Almudaina no correspondían a Beatriz, pues tan solo las tenía en empeño mientras esperaba que le fueran satisfechos 200.000 sueldos por su dote. De hecho, el rey las había entregado a Pedro de Jérica y no era factible su restitución. Sin embargo, Beatriz alegaba que, aunque no fuese propietaria, antes de la guerra poseía de forma efectiva aquellas localidades y cobraba sus rentas ${ }^{88}$. El legado pontificio respaldó sus quejas y el rey aragonés terminó por manifestarse en el mismo sentido ${ }^{89}$. En noviembre de 1361 ordenó a Pedro de Jérica la devolución ${ }^{90}$. Nunca se hizo, pues la guerra con Castilla no tardó en volver.

Lo cierto es que los asuntos valencianos quedaban cada vez más lejos para Beatriz, ocupada en gestionar su viudedad. Como advertimos anteriormente, en el momento de su casamiento, Beatriz recibió de su esposo, entre otros bienes, la mitad de los lugares leoneses de Rodelga y Quintanilla. Resulta significativo que Pedro Ponce de León señalara estos bienes. El linaje ya estaba implantado definitivamente en Andalucía y los lazos con su pasado leonés no tardarían en desaparecer. De hecho, pese a la consideración de bienes dotales, el señor de Marchena había decidido prescindir en vida de aquellos lugares y del resto de sus posesiones leonesas y asturianas. Lo hizo mediante un trueque con sus sobrinos Pedro, Juan y Leonor, hijos de Fernán Pérez Ponce, maestre de Alcántara ya difunto. No obstante, Beatriz no podía quedar sin compensación. $\mathrm{Su}$ esposo le da entonces la mitad de Bollullos y de Montañina en emienda de los dichos logares que a ella eran tenidos e obligados e por muchos buenos seruiçios que me fizo e me faze $e^{91}$. Aquella jurisdicción, en la actual provincia de Huelva, perteneció originalmente a María Alfonso Coronel, la esposa de

${ }^{86}$ Ibidem.

${ }^{87}$ Costa 1998, pp. 517-519, doc. 314.

88 Ibidem, p. 249.

${ }^{89}$ El legado, "ad quem huiusmodi dubii et consimilium declaracio pertinebat", escribe al rey el 20 de octubre de 1361 "super restitucione locorum de Planes et de Almudayna fienda nobili Beatrici de Loria, uxori nobilis Petri Poncii de Leone", y concluye que "castra predicta et loca dicte nobili fore restituenda et reintegranda" (ibidem, p. 523, doc. 318). El rey ordenó la restitución el 3 de noviembre (ibidem, p. 525, doc. 321).

${ }^{90}$ Curiosamente, en el otoño de 1361 se pensó en un posible matrimonio entre Juan de Ampurias, el hijo de María Álvarez y sobrino de nuestra Beatriz, y Beatriz de Jérica, hija y heredera de Pedro de Jérica. El rey escribió sobre esta cuestión a Pedro de Jérica el 3 de octubre. A finales de noviembre continúan las gestiones a la espera de la preceptiva dispensa, pero el matrimonio no llegó a celebrarse (ibidem, pp. 276, 521-522, doc. 317, y 526, doc. 323).

${ }^{91}$ AFCMS, leg. 917, primer documento. $C f$. Ladero 1992, pp. 79-80; AFCMS, leg. 4292. 
Guzmán el Bueno, que la dejó en testamento a su hija Isabel, casada con el primer señor de Marchena. De ella pasaría a su hijo; y de este, a Beatriz de Lauria. Se trata de una donación perpetua, por juro de heredad, pero con ciertas condiciones: solo sería así guardando ella su bibdedat e su castidat e aquellas posturas e condiçiones que conmigo ouo al tienpo que yo e ella casamos ${ }^{92}$. El documento está firmado en Marchena el 17 de mayo de 1352. Algunos meses más tarde, el 6 de noviembre, don Pedro otorgó un codicilo con sus últimas disposiciones testamentarias, estando doliente de la dolençia de que finó. Una de las cláusulas de dicho documento contenía la donación de las salinas de Tarfía a su esposa, al tiempo que ratificaba la entrega de Bollullos en compensación por la pérdida de Rodelga y Quintanilla ${ }^{93}$. Así, pues, el segundo señor de Marchena entregó a sus sobrinos todas sus posesiones en tierra de León e Tierra de Campos e en Asturias e en Gallizia e en todas sus merindades. A cambio, había recibido la mitad de las salinas de Tarfía y la mitad de Bornos (que pertenecieron a su hermano, el maestre de Alcántara), así como 80.000 maravedíes, de los cuales 70.000 se pagaron con la entrega de la mitad de Bollullos y Montañina y de las casas de Jerez de la Frontera que dicen de don Ferrando, y los restantes 10.000 , en dinero. Beatriz reconoció y consintió la transacción ${ }^{94}$.

Con el trueque, Beatriz ganaba proximidad a su nuevo señorío, lo que se traduce siempre en mejor control y mayor aprovechamiento, pero veía menoscabada la entidad de su exiguo patrimonio personal. Tanto en el caso de Rodelga y Quintanilla, como en el de Bollullos y Montañina, solo le correspondía la mitad de la jurisdicción, pero resulta difícil conceder entidad poblacional al último de estos lugares, que no era más que una explotación agrícola, y muy deteriorada, como veremos. Estas posesiones compartidas eran fruto, por lo general, de transmisiones hereditarias previas, pero limi-

\footnotetext{
${ }_{92}$ AFCMS, leg. 917, primer documento. Curiosamente, el señor de Marchena se refiere a su esposa como "Beatriz de Xérica".

${ }_{93}$ El documento dice así: "e mando las mis salinas de Tarrfía e la mi meytad de Bollullos con todos sus derechos, segunt que lo yo avía bien e conplidamiente, a doña Beatriz, mi muger, e mándogelas con todas sus rentas e con todos sus derechos bien e conplidamiente por emienda de Rodelga e de Quintanilla, que son en el regnado de León, en término de Benauente, que yo le abía a ella dado en sus dotes segunt fuero de Aragón, la qual meitad destos dichos lugares yo compré de Alffón Ferrández, tutor de Iohán Ponze e de Leonor Ponze, fijos del maestre mi hermano; e otrosý por muchos serviçios e bonos que esta doña beatriz me fizo le mando esto que dicho es manteniendo ella biudidat; e non manteniendo biudidat, que torne a mi fijo don Iohán" (AFCMS, leg. 917, segundo documento).

${ }^{94}$ AFCMS, leg. 917, tercer documento. En la fecha no es legible el año. Solo sabemos que se otorgó en Marchena un jueves 17 de mayo. Dado que el documento de cesión de Bollullos a Beatriz de Jérica está fechado también en Marchena el jueves 17 de mayo de 1352, cabe pensar que ambos se realizaran al mismo tiempo. De hecho, en la concesión a Beatriz, su esposo alude a Bollullos, "que yo agora troqué con los dichos mis sobrinos" (AFCMS, leg. 917, primer documento).
} 
taban considerablemente la capacidad de acción del poseedor, sobre todo, si en algún momento se planteaba su enajenación. En cualquier caso, las experiencias vividas harían que Beatriz recelase de señoríos hipotéticos, lejanos o virtuales, por lo que quiso, desde un primer momento, proceder a la partición de la jurisdicción sobre Bollullos y Montañina, con una delimitación precisa de la mitad que le correspondía.

La otra mitad del señorío sobre Bollullos y Montañina pertenecía a don Alonso Pérez de Guzmán, hijo y heredero del segundo señor de Sanlúcar de Barrameda, Juan Alonso de Guzmán, y nieto, por tanto, de Guzmán el Bueno. Recordemos que Juan Alonso de Guzmán había casado con Beatriz Ponce de León, hermana del primer señor de Marchena, y que tuvieron un hijo. Tras la muerte de este hijo en 1330 y de la esposa al año siguiente, Juan Alonso casó en segundas nupcias, en 1336, con Urraca Osorio, hija de Álvar Núñez Osorio, conde de Trastámara ${ }^{95}$. Él rondaba los cincuenta años, y ella los veinte. Entre la batalla del Salado y la conquista de Algeciras nacieron dos hijos: Alonso Pérez de Guzmán, que será tercer señor de Sanlúcar entre 1351 y 1365, y un nuevo Juan Alonso de Guzmán, que sucederá a su hermano como cuarto señor de la localidad hasta 1396. A todos ellos aluden los documentos sobre la partición de Bollullos y Montañina, pues los hijos de don Juan Alonso eran menores de quince años y su madre, Urraca Osorio, actúa como tutora.

Urraca Osorio y Beatriz de Lauria enviudaron con solo un año de diferencia: en 1351 la primera y en 1352 la segunda. Ponces y Guzmanes se encontraban en aquellos momentos muy próximos. En principio, los vínculos familiares y la sintonía que se observa entre ambos linajes durante casi todo el siglo XIV podrían haber facilitado las cosas a Beatriz, pero no fue así. La respuesta de los Guzmán a la solicitud de partición de Bollullos y Montañina debió ser negativa, pues el 18 de febrero de 1354, los procuradores de ambas partes comparecen en juyzio ante Pedro Sánchez, alcalde teniente las vezes de García Jufre de Tenorio, alcalde mayor de Sevilla. El procurador de Beatriz de Lauria es Alfonso Fernández de Onís, alcalde mayor de Marchena, al que otorga en dicha villa, el 15 de febrero, una carta de personería con el único objetivo de conseguir la partición y tomar posesión en su nombre de la mitad que le correspondiese. El procurador de la parte contraria es Alfonso López, quien representa, conjuntamente, a Urraca Osorio y sus hijos, mencionados como Alfonso Pérez (Alonso Pérez de Guzmán) y Juan o Juan Alfonso (Juan Alonso de Guzmán) ${ }^{96}$. Los cometidos del procurador de los Guzmán parecen ser más diversos, pues la correspondiente carta de poder no circunscribe su

${ }^{95}$ Ladero 2015, pp. 57-58.

${ }^{96}$ AHNOB, Osuna, CP. 76, D. 1. 
actuación al asunto de Bollullos y Montañina ${ }^{97}$. Si el procurador de Beatriz es alcalde mayor de Marchena, capital señorial de los Ponce de León, el de Urraca se presenta exclusivamente como criado del alcalde Juan Fernández. Es interesante observar que las respectivas cartas de poder están fechadas en Marchena y Sanlúcar de Barrameda, capitales señoriales de los Ponce de León y los Guzmán y, según parece, lugares de residencia de ambas viudas en este momento, a una distancia prudente de Sevilla. Recordemos los recelos que produjo tanto entre los Guzmán como entre los Ponce de León el acceso al trono de Pedro I de Castilla. El tiempo se encargaría de darles la razón ${ }^{98}$.

Cuando en febrero de 1354 comparece en Sevilla el procurador de Beatriz de Lauria, solicita que se realice la partición, que acuda el procurador de la parte contraria y que echasen en vno suertes para que cada vno dellos conosçiese la su meytad y fiziese de lo suyo lo que quesiese. Sorprendentemente, el procurador de los Guzmán dice estar de acuerdo, aunque no acudirá al reparto, y exige que Beatriz demuestre la posesión del señorío. Ambos representantes solicitan finalmente al teniente de alcalde mayor de Sevilla que mandase a los partidores e alarifes del conçeio desta dicha çibdat que se desplacen a Bollullos para realizar la partición, a lo que Pedro Sánchez accede. El mismo 18 de febrero está fechado un albalá suyo ordenando a los partidores de las heredades y alarifes del concejo, de parte del dicho sennor rey y del dicho alcalde Garçía Jufre, que partan los lugares y deslinden cada mitad por sus términos e mojones çiertos, tras lo que deben comunicarle el resultado de los trabajos ${ }^{99}$. Nos consta que el alcalde mayor García Jofre Tenorio expidió otro albalá contraviniendo la orden de su sustituto, que respondió el 28 de marzo con un nuevo documento reiterando la orden inicial.

La partición se realizó finalmente el 4 de abril ${ }^{100}$. Ese día se reunieron en el cementerio de la iglesia de Bollullos, do está el mojón de la cruz en que se parte por meytad la dicha aldea, el partidor Alfonso Ordóñez y los alarifes Adán y Juan Martínez, en presencia del escribano público y de los regidores

\footnotetext{
97 Urraca Osorio lo designa como "mío personero e mío adelantado e mío çierto sufiçiente qunplido procurador en todas mis bozes e en todas mis razones e de los dichos mis fijos", así "en los pleytos mouidos commo en los por mouer, judgados e por judgar", tanto "con cartas commo syn cartas o en otra manera qualquier que sea". A diferencia de la carta de poder del procurador de Beatriz de Lauria, fechada solo tres días antes de la comparecencia ante el alcalde mayor de Sevilla, la del de Urraca Osorio fue expedida en Sanlúcar de Barrameda el 28 de enero de 1353, un año antes, tal vez al hilo de algún otro asunto.

${ }_{98}$ Carriazo 2002, pp. 64-67.

99 AHNOB, Osuna, CP. 76, D. 1. El documento queda aquí interrumpido, no sin antes advertir que tres días después, el 21 de febrero, volvió a comparecer ante Pedro Sánchez el procurador de Beatriz de Lauria, corroborando que es su representada quien lleva la iniciativa judicial en todo momento.
}

${ }^{100}$ AHNOB, Osuna, CP. 76, D. 2. 
de la localidad. Acudió, evidentemente, el procurador de Beatriz de Lauria, pero no el de Urraca Osorio, por lo que su hijo, el señor de Sanlúcar, fue declarado en rebeldía. Siguiendo la orden recibida, partidor y alarifes dividen el caserío en dos partes. Una de ellas incluye las casas del palaçio, que cabe identificar, por la denominación, con una residencia señorial de cierta entidad, al menos en comparación con el resto de edificaciones del lugar. La otra parte incluía las casas de Montannina con su cortijo, saluo el molino para moler azeytuna que está aparte del dicho cortijo y se reserva para un uso compartido por ambos señores, que se repartirían, además, las tierras de la heredad (olivares, alcornocales, huertas e higuerales). Vemos, pues, que la consideración de Montañina como lugar era bastante generosa. Quien se quedase con el cortijo debía recibir de la otra parte una compensación de mil maravedíes para ayuda de reparar las dichas casas e corrales, que están derribados. Los lotes se sortearon y a Beatriz le correspondió el que incluía el cortijo de Montañina, del cual tomó posesión su procurador.

Durante siete años, Beatriz fue señora de una mitad concreta de la población, hasta el punto de que, cuando en 1361 proceda a su venta, los documentos hablarán del barrio de donna Beatriz de Loria ${ }^{101}$. Antes, hubo de afrontar otro asunto de más enjundia y mayor complejidad: su derecho sobre la villa, rentas y heredades de Marchena. Conservamos el texto del acuerdo al que llegó con su hijo Juan Ponce de León, legítimo sucesor del difunto señor de Marchena, que no había alcanzado aun los veinte años de edad. El documento está fechado en Sevilla, no en Marchena, el 14 de junio de 1357 $7^{102}$. Recordemos que el esposo de Beatriz había fallecido en 1352. Cinco años después, madre e hijo se enfrentaban en un pleito que zanjaron de manera amistosa con dicho acuerdo. En estos momentos, Juan Ponce de León gozaba de gran reconocimiento, al haber sofocado, junto con la milicia sevillana, la sublevación de Juan de la Cerda, señor de Gibraleón ${ }^{103}$. Sabemos que Pedro Ponce de León había incluido Marchena en las arras de Beatriz de Lauria. Así lo reconoce su hijo cuando alude al tiempo en que Beatriz tenía la villa en su poder por razón de las vuestras arras o por vuestro dote, según que el dicho don Pedro Ponze, mío padre, vos la dio. Así lo afirma Beatriz cuando recuerda que tenía Marchena en la manera que lo el dicho don Pedro Ponze vuestro padre ordenó y estableció, y por la manda y postrimera voluntad que el dicho don Pedro Ponze, que Dios perdone, en esta razón fizo.

${ }^{101}$ AGFCMS, leg. 917, quinto documento.

102 AHNOB, Osuna, CP. 74, D. 9, copia simple en C. 169, D. 9. De aquí proceden las citas siguientes.

${ }^{103}$ López de Ayala, Crónica, vol. I, p. 253. 
Y así lo sancionó el rey, Pedro I, con las cartas que envió a Beatriz para asegurar que percibía todas las rentas y pechos y derechos de la dicha villa de Marchena y de su término fasta que el dicho pleyto fuere librado entre nos las dichas partes por sentencia como deue. Beatriz de Lauria dice más: que tuvo Marchena después que el dicho don Pedro Ponze finó y hasta que rubricó el acuerdo con su hijo. Resulta significativo que la carta de poder dada por Beatriz a su procurador, en Marchena, el 15 de febrero de 1354, para gestionar la partición de Bollullos y Montañina estuviese firmada por dos escribanos que, en ambos casos, se identifican como escribanos públicos de Marchena por mi sennora donna Beatriz ${ }^{104}$.

Sin embargo, la posesión no fue siempre efectiva, pues su hijo reconoce que ponía enbargo algunas vezes y embargaba las dichas rentas y pechos y derechos diciendo que me pertenecian; lo cual también había sido avalado por Pedro I, porque me diera el dicho señor rey otra su carta en que mandana que me recudiessen con las dichas rentas e pechos y derechos ${ }^{105}$. Dado que el monarca había justificado una situación y la contraria, madre e hijo quedaron abocados a la solución judicial. El hecho de que tanto una como otro dispusieran de los documentos reales indica que, en un primer momento, no pudo solventarse el conflicto en el marco estrictamente familiar, y que ambas partes confiaban en que la decisión del rey invalidase las pretensiones del contrario. Solo cuando comprobaron que no fue así, se avinieron a alcanzar una solución de mutuo acuerdo. Hasta entonces, sostuvieron pleyto y contienda por el señorio y las rentas y derechos de la villa de Marchena y heredades que con ella andan y a ella pertenecen.

En el documento, Beatriz aparece y se manifiesta siempre antes que su hijo, desde una posición de superioridad que se refuerza cuando dice renunciar a unos derechos que yo auía y auer debía por facer ayuda a vos el dicho don Joan Ponze, mi fijo. Frente a este gesto, el hijo, como ya hemos comentado, admitía haber embargado algunas vezes las rentas de Marchena diciendo que le pertenecían. Nótese que no afirma que realmente le pertenecieran, aunque disponía también de cartas reales a su favor y, en última instancia, había tenido la capacidad de embargar las rentas, lo que supone un reconocimiento a su autoridad por parte del concejo. La renuncia de Beatriz de Lauria tenía, eso sí, condiciones. Sería efectiva siempre y cuando su hijo tuviese descendencia. Si moría sin hijos legítimos -lo que Dios no quiera, apunta Beatriz-, el señorío volvería a la madre. A cambio, Beatriz recibiría de su hijo quince mil maravedíes forros y quitos de chançillería e de descuento y de toda otra

${ }^{104}$ AHNOB, Osuna, CP. 61, D. 1. Estos escribanos eran Gonzalo Martínez y Pedro Gómez. El escribano que firma la carta de poder de Urraca Osorio lo hace como "escribano público de Sanlúcar de Barrameda por don Alfón Pérez de Guzmán”, pese a su minoría de edad.

${ }^{105}$ AHNOB, Osuna, C. 169, D. 9. 
razón, aqui en Seuilla, en vuestra posada. Cabe pensar que, a partir de entonces, Sevilla se convertiría en su residencia habitual. Los quince mil maravedíes los sitúa Juan Ponce de León en el almojarifazgo desta dicha ciudad, en la tierra que yo oy día tengo del dicho señor rey y en la que me pusiere de cada año, y se abonarían por los tercios del año ${ }^{106}$. En caso de que Juan muriese antes que su madre, sus herederos debían seguir pagando a Beatriz la misma cantidad. Juan Ponce de León era quien salía beneficiado, pues reconoce que lo que Beatriz cedía vale mucho más que lo que vos e a dar yo de lo mío mismo para vuestra prouisión de cada año. El documento incluye unas muy severas cláusulas de sanción material como garantía de cumplimiento.

Tenemos, por tanto, a Beatriz de Lauria, cinco años después de la muerte de su esposo, residiendo en Sevilla, con una renta anual de quince mil maravedíes y un pequeño señorío en tierras onubenses. Al cabo de otros cinco años, se desharía también de aquella posesión. El 17 de agosto de 1361, en Sevilla, acabó vendiendo la mitad de Bollullos y Montañina a Urraca Osorio, que completaba así la posesión de la aldea para su hijo ${ }^{107}$. Beatriz recibe 30.000 maravedíes. Si tenemos en cuenta que Pedro Ponce de León valoró ambas posesiones y las casas de Jerez en 70.000 maravedíes cuando procedió al trueque con sus sobrinos, resulta evidente que, o el señor de Marchena trató muy ventajosamente a los hijos de su hermano, o Urraca Osorio supo aprovechar la necesidad o la urgencia por vender de Beatriz.

La venta se realizó el 17 de agosto. Al día siguiente, Urraca encargó a su procurador que tomara posesión en su nombre del señorío adquirido. El 19, Beatriz designa al suyo para la entrega, que se realiza en Bollullos el día 20. Según el documento, el representante de Beatriz y muchos vecinos de la población se juntaron en concejo, a campana tañida, en el portal de la iglesia de Santiago, en el barrio de donna Beatriz de Loria, donde, en presencia de un escribano local y de otros venidos desde Sevilla, tomó posesión el enviado de Urraca Osorio. Curiosamente, el escribano de Bollullos, Alfonso Martínez, es presentado como escribano público del dicho barrio. Los vecinos enumerados (un jurado, un mayordomo y catorce hombres más) resultan ser vezinos e moradores del dicho logar de Bollullos, del barrio de la dicha donna Beatriz. Ante ellos, se procede a la lectura de una carta dirigida por la antigua señora a las autoridades locales el día anterior, que explica el motivo de la venta:

106 "E si por auentura el rey nuestro señor me tirase la tierra que dél tengo en el dicho almojarifazgo, o non me la quisiese ý poner o acaeciere otra cosa por que yo non obiese la dicha tierra en el dicho almojarifazgo, que los dichos quinze mil maravedís que los ayades de las rentas y pechos y derechos de la dicha villa de Marchena y de su término y de los otros mis lugares do vos la dicha doña Veatriz más quisiéredes" (ibidem).

107 AGFCMS, leg. 917, cuarto documento. $C f$. Ladero 1992, p. 80. 


\begin{abstract}
De mí, doña Beatriz de Loria, a los alcalldes e el alguazil e jurados e omes bonos del conçeio de Bollullos, en la parte que yo ý he, salut commo aquellos de quien fío e para quien querría muncha onrra e buena ventura, sepades que yo, por acorrer a don Iohán Ponçe, mi fijo, para le prestar algunos maravedís que auía muncho menester, que vendí a donna Vrraca, muger que fue de don Iohán Alfonso de Guzmán, toda la parte e derecho e voz e razón que yo auía en el dicho logar de Bollullos e en Montañina e en sus términos bien e conplidamente, segunt que lo yo ý auía, por vna contía de maravedís que della resçebí, segunt más conplidamente se contiene en la carta de la dicha vendiçión, por que vos mando que de aquí adelante que resçibades e ayades por sennora a la dicha donna Vrraca ${ }^{108}$.
\end{abstract}

Tanto la cesión de Marchena como la venta de Bollullos y Montañina son muestras de generosidad de Beatriz hacia su hijo, pero también servicios al linaje de su esposo, que viviría pocos años después los momentos más difíciles, con la ejecución pública de Juan Ponce de León en 1367, por orden de Pedro I, en la sevillana plaza de San Francisco ${ }^{109}$. Este episodio, junto con el asalto y saqueo de Marchena por los granadinos poco tiempo después, constituyen la antítesis de la época de esplendor vivida por el linaje durante la década de 1340. Fue entonces, hacia 1347, cuando Pedro Ponce de León y Beatriz de Lauria convirtieron en solar espiritual del linaje el convento de San Agustín de Sevilla ${ }^{110}$. No se trataba de una fundación exnovo, comoen el caso de San Isidoro del Campo y los Guzmán, sino de un edificio ya existente cuya comunidad propuso a los herederos de Arias Yáñez de Carranza que cediesen el patronato a Pedro Ponce de León. La iglesia conventual albergaría el panteón de los señores de Marchena, aunque se pactó que no eliminasen los emblemas heráldicos de los Carranza. Todos salían beneficiados: los antiguos patronos soltaban una pesada carga económica que ya no podían sostener, el nuevo protector encontraba por fin un lugar de enterramiento idóneo para él y para su esposa, y el convento se aseguraba nuevas limosnas y donaciones que permitirían continuar las obras. De los pocos restos del antiguo edificio que han sobrevivido hasta hoy destaca el refectorio, con un cuidado programa iconográfico que incluye motivos heráldicos tales como el león rampante, el águila explayada, los castillos y leones del reino, y el emblema heráldico de Beatriz: las barras de Aragón con la bordura de escudetes fajados de la casa de Vidaurre ${ }^{111}$. Sin embargo, no sería allí donde reposarían los restos mortales

108 AGFCMS, leg. 917, quinto documento.

109 López de Ayala, Crónica, vol. II, p. 221.

${ }^{110}$ Carriazo 2002, pp. 87-90.

111 Martínez de Aguirre 1992; Carriazo 2002, pp. 90-102. 
de Beatriz, sino en otra fundación sevillana: el monasterio de Santa María de Dueñas ${ }^{112}$.

\section{RETIRO Y MUERTE}

Fundado a mediados del siglo XIII, probablemente por el aragonés Juan Mathe de Luna, bajo la regla cisterciense, Santa María de Dueñas dispuso de un archivo que ha llegado a nosotros muy mermado por las vicisitudes sufridas por la comunidad a partir de 1868, y que se conserva en el monasterio de Santo Domingo de Silos "el Antiguo" de Toledo"13. En un Libro de memorias y capellanías del monasterio de Dueñas consta que Beatriz de Gérica, a la que se identifica como bisabuela del duque de Cádiz (en alusión al célebre Rodrigo Ponce de León), acabó monja en este monasterio y que se le dice una misa en noviembre ${ }^{114}$. Se anota seguidamente que sus herederos deben traer el día de Todos los Santos doscientos maravedis y dos hachas, y cubrir su sepultura ${ }^{115}$. La propia Beatriz dio al monasterio en limosna 150 florines de oro de una vez ${ }^{116}$. Un manuscrito sobre Familias de Aragón atribuido a Jerónimo Zurita comenta que Beatriz fue monja en Santa María de las Dueñas y estuvo en el dicho monasterio veinte años ${ }^{117}$. Allí hizo su testamento, año MCCCCXII

${ }_{112}$ Según Pedro Salazar de Mendoza, el más importante de los cronistas de los Ponce de León, Beatriz fue enterrada en la cartuja de las Cuevas de Sevilla, y luego trasladada a Santa María de Dueñas (Salazar, Crónico, f. 87r; sobre el cronista, véase Gómezy Sánchez 2015). Diego Ortiz de Zúñiga, el gran historiador de la Sevilla del Barroco, le corrigió con ironía: "largos años debió sobrevivir a su marido, pues el convento de la Cartuxa no se fundó hasta adelante del año 1400; creo que fue al contrario" (Ortiz de Zúñiga 1988, p. 131). No tenemos constancia de que el cuerpo de Beatriz fuera trasladado en ningún momento a la Cartuja.

113 Borrero 2004, pp. 51-68.

114 Agradezco a la profesora Borrero Fernández que me haya facilitado las noticias sobre Beatriz de Lauria contenidas en este "libro protocolo con las memorias y capellanías perpetuas", fechado en 1633 y conservado en el Archivo del Monasterio de Santo Domingo de Silos de Toledo, Sección Sevilla, 63, f. 7.

${ }^{115}$ En el testamento de su bisnieto Juan Ponce de León, fechado en 1469, leemos: “otrosý do en Santa María de las Duennas de la dicha çibdad de Seuilla ofrenda e çera el dicho día de Todos Santos por donna Bieatriz de Xérica, mi bisabuela, que está en el dicho monesterio" (Carriazo 2003, p. 179, n. ${ }^{\circ}$ 5/21). En 1492, el hijo de este, Rodrigo Ponce de León, recuerda también en su testamento esta obligación hacia "el monesterio de Santa María de Duennas, por donna Beatriz de Xérica, visabuela del dicho sennor conde mi padre, que allí está sepultada" (ibidem, p. 239, n. $^{\circ} 6 / 20$ ).

116 Borrero 2004, p. 58, n. 23.

117 RAH, Colección Salazar y Castro, C-36 (signatura moderna: 9/259), f. 9r. Al comienzo del manuscrito encontramos la nota siguiente: "Digo yo, el doctor Juan Francisco Andrés, que el Memorial y registro de las casas antiguas de Aragón lo copié del original del secretario Gerónimo Çurita, cuya letra conozco por hauer visto su firma, y para que este MS tenga la autoridad que merecen las obras deste insigne historiador certifico ser esto verdad, y lo firmo de mi mano en Çaragoça, a 21 de febrero del año 1639. El doctor Juan Francisco Andrés" (ibidem, f. 3r). 
$y$ dexó por heredero a D. Pedro Ponçe, su hijo. La fecha consignada resulta tardía en exceso e hizo pensar a Costa i Paretas que el dato se refería a otra Beatriz, sobrina de la nuestra e hija de su hermano Pedro ${ }^{118}$. Personalmente, considero que en el manuscrito copiado en 1639 no se indicó que se trataba del año de la Era, por lo que la fecha correcta no sería 1412, sino $1374^{119}$. La noticia de que Beatriz dejó por heredero a su hijo Pedro casa bien con esta opción, pues el primogénito, Juan, había muerto en 1367. El testamento de Pedro Ponce de León, cuarto señor de Marchena, está fechado, precisamente, el 7 de diciembre de 1374 y deja claro que su madre ya había fallecido en esa fecha ${ }^{120}$.

El manuscrito atribuido a Zurita consigna también que Beatriz (a la que denomina Beatriz de Lauria) hizo donación del derecho que tenía y le pertenecía en el castillo y villa de Cocentaina y Pinella (sic) a su hijo Pedro. Supuestamente, la donación se habría hecho en Marchena el año de MCCCXCIII, es decir, $1355^{121}$. Ya hemos visto que el documento se conserva y está fechado en Marchena el 10 de marzo de $1359^{122}$. Si damos crédito a la noticia de los veinte años de monja y pensamos que pudo testar en 1374, su retiro en Santa María de Dueñas debió producirse no muchos años después de enviudar. En el acuerdo de 1357 por el que cedía las rentas de Marchena a su

Es lástima que otro manuscrito de la misma colección, titulado "Casa de Exerica, procedida legítimamente de la Real de Aragón, cuya sangre y armas se conservan en la de los Ponces de León" no alcance a incluir a nuestra Beatriz (RAH, Col. Salazar y Castro, B-26, signatura moderna 9/141, ff. 173-201).

118 Costa 1998, p. 278, n. 74. Posteriormente, la propia autora corrigió esta identificación, aunque sin resolver el problema de la fecha (Costa 2001, p. 673).

119 Según el manuscrito, la noticia sobre la permanencia de Beatriz como monja durante veinte años "parece por auto y fe de doña Elvira Hernández, abadesa del monasterio y convento de las Dueñas de Sevilla". Dicho auto "testificóse año MCCCXXI", que podría ser 1383 (RAH, Salazar y Castro, C-36, f. 9r). No hemos podido corroborar con otra documentación la existencia de esta abadesa, pues los documentos del siglo XIV conservados en el monasterio toledano de Santo Domingo de Silos son muy escasos.

${ }^{120}$ Carriazo 2003, pp. 113 (1/16), 116 (1/49). Resulta interesante constatar que Santa María de Dueñas fue también lugar de refugio para algún otro personaje femenino vinculado al linaje, aunque no tan ilustre. En 1401 hizo testamento un nieto de Beatriz de Lauria, hijo ilegítimo de Pedro Ponce de León, llamado Fernando. Su madre se llamaba Mari Sánchez y acabó "monja de Santa María de las Dueñas" (ibidem, p. 126, n. ${ }^{\circ}$ 2/14).

${ }^{121}$ La escritura de concesión estaría "testificada por Rodrigo Alonso, notario". Avala nuestra suposición otra fecha que proporciona seguidamente el referido manuscrito. Tratando sobre Pedro Ponce de León, el hermano y sucesor de Juan, comenta que casó con Sancha de Baeza y que esta era "curadora" del hijo de ambos, también llamado Pedro, en 1420. La fecha correcta debe ser 1382, pues el marido de Sancha murió en 1374. En 1420 este nuevo Pedro tenía más de cuarenta y seis años, y no necesitaba tutora de ningún tipo. Es más, Sancha de Baeza debió morir en los primeros años del siglo XV.

${ }^{122}$ ADM, Cocentaina, leg. 1, n. ${ }^{\circ}$ 9. El documento lo redactó, efectivamente, Rodrigo Alfonso, escribano público de Marchena. Actuaron como testigos "Alfonso Ferrández, alcalde mayor de don Johán, Gonçaluo Ferrández, hombre del dicho alcalde, García Alfonso, alguazil, e Pero Ferrández de Muedra". 
hijo Juan consta que se firmó aquí en Seuilla, en vuestra posada, sin aludir expresamente al monasterio ${ }^{123}$.

La ruptura de los lazos con los señoríos andaluces casa bien con la actitud propia de quien ha optado definitivamente por un retiro monacal. Ahora bien, hasta el último momento, Beatriz de Lauria siguió preocupada por el destino de sus pretendidos señoríos valencianos. En 1355 intentó asumir de manera efectiva el control de Cocentaina y Penella. En 1359 hizo donación de estos lugares a su hijo segundo, Pedro, que se convertirá en nuevo señor de Marchena tras la muerte de su hermano Juan en 1367. Pasaban los años y Beatriz era consciente de que ni ella ni sus descendientes verían reconocidos sus derechos ${ }^{124}$. El 20 de enero de 1373, ante un escribano público de Sevilla, hace un último intento por resolver la cuestión, entregando toda la mi parte e derecho e boz e razón sobre Cocentaina y Penella, con sus términos, aldeas y alquerías, a don Juan, conde de Ampurias, hijo de su hermana María Álvarez $^{125}$. Le cede también todos los derechos e rentas e frutos e esquilmos desde el cada vez más lejano día de la muerte de Alfonso Roger de Lauria, lo que indica que no llegó a percibir nada por estos conceptos. Beatriz justifica la donación al conde de Ampurias:

por quanto sodes mi sobrino e por muchas onrras e buenas obras que yo de uos reçebí e reçibo oy día, tantes e tantas de que me otorgo e tengo por muy bien pagada e entregada e encargada a toda mi voluntad ${ }^{126}$.

El documento recuerda necesariamente al que contenía la infructuosa donación de estos mismos lugares a su hijo Pedro Ponce de León, aunque no establece ningún tipo de compensación económica ni tampoco la obligación de asumir el apellido y blasón de los Lauria. A la expedición del documento en Sevilla asistió Jaime Pujol, criado y procurador del conde de Ampurias, lo que evidencia un acuerdo previo entre Beatriz de Lauria y su sobrino, alcanzado forzosamente con el visto bueno del señor de Marchena. Paralelamente, también se había negociado con los Jérica. La hija de Pedro de Jérica, una nueva Beatriz, da orden al alcaide de Cocentaina, en junio de 1373, para que

${ }^{123}$ AHNOB, Osuna, C. 169, D. 9.

${ }^{124}$ Fullana critica la "injusta donación" de Cocentaina por Pedro IV a Juan Alonso de Jérica, hijo bastardo de Pedro de Jérica, revocada dos años después. La hija legítima y heredera de este último, Beatriz de Jérica, entregaría la baronía a su tía, Beatriz de Lauria, el 9 de noviembre de 1372 (Fullana 1923, p. 158).

${ }_{125}$ ADM, Cocentaina, leg. 1, n. ${ }^{\circ}$ 5. Paz y Melia da noticia de esta donación, pero, al fecharla en 1411, sin la preceptiva conversión, dificulta la comprensión del proceso (1915, p. 335).

${ }^{126}$ ADM, Cocentaina, leg. $1, \mathrm{n}^{\circ} 5$. 
entregue castra et loca de Cocentayna et de Penella al conde de Ampurias ${ }^{127}$. Con ello, aunque de manera indirecta, se reconocía el derecho de Beatriz de Lauria al señorío que nunca pudo disfrutar. Poco después, murió Beatriz, y, a finales de 1374, su hijo Pedro. En el testamento de este último, fechado el 7 de diciembre de dicho año, leemos lo siguiente:

E otrosí, mando e tengo por bien que sy se cobraren las dos mill doblas de oro castellanas que don Juan, conde de Anpurias, deue e ha de dar a donna Beatriz de Luria, mi madre, que Dios perdone, que destas dichas doblas que paguen e cunplan el testamento e manda que la dicha donna Beatriz mi madre fizo e ordenó segund que en él se contiene ${ }^{128}$.

Estas 2.000 doblas de oro que el conde de Ampurias y sobrino de Beatriz adeudaba a su tía debían constituir la indemnización por aquel señorío perdido. La propia expresión sy se cobraren refleja el escepticismo de Pedro Ponce de León, que vincula a su obtención el cumplimiento completo y efectivo del testamento materno. Por lo demás, Pedro Ponce de León no menciona en su testamento el señorío de Cocentaina, que sí reclamarán, sorprendentemente, su hijo y su nieto ${ }^{129}$.

\section{CONCLUSIÓN}

El matrimonio con Beatriz de Lauria reportó a Pedro Ponce de León la notoriedad política y social que pretendía, y que sus descendientes continuaron rentabilizando a través de la heráldica y la literatura genealógica del linaje. Esta memoria visual y escrita terminó convirtiendo a Beatriz en un apellido, una ascendencia y el pretexto para terminar de dar forma al emblema heráldico familiar. Pero, al mismo tiempo, en las crónicas de la casa de Arcos se desvanecía el recuerdo de su propia existencia histórica. La reconstrucción de los años andaluces del personaje nos permite constatar cómo, tras las décadas de 1330 y 1340, que resultaron esenciales para la consolidación de los grandes linajes sevillanos al calor de la actividad militar en la frontera, la de 1350 abre un tiempo nuevo. En primer lugar, por el acceso al trono de Pedro I y los recelos que ello provocó entre los familiares de Leonor de Guzmán, pero también, por la muerte, en corto espacio de tiempo, de los señores de Sanlúcar de Barrameda y de Marchena, que dejó al frente de sus respectivas casas a dos

${ }^{127}$ ADM, Cocentaina, leg. 3, n. ${ }^{\circ} 2$.

${ }^{128}$ Carriazo 2003, p. 116, n. ${ }^{\circ} 1 / 49$.

${ }^{129}$ Ibidem, pp. 86-87. 
mujeres: Urraca Osorio y Beatriz de Lauria. En el primer caso, por la minoría del heredero; en el segundo, por los compromisos matrimoniales, que hacían a Beatriz señora de Marchena.

Aun no se había olvidado la enorme influencia familiar, social y política de María Alfonso Coronel, la viuda de Guzmán el Bueno, fallecida veinte años antes, cuando vemos a otras dos mujeres tomando decisiones importantes en beneficio de sus respectivas casas. Si María Alfonso Coronel hizo frente a la complicada minoría de Alfonso XI, Urraca Osorio y Beatriz de Lauria sufrieron la violencia del rey Cruel. La primera perdió la vida; la segunda vio morir a su primogénito, recluida en el monasterio de Santa María de Dueñas de Sevilla. Esta reclusión monástica brindó, sin duda, protección a Beatriz, que nunca abandonó por completo los asuntos familiares, sobre todo, por lo que respecta a la reclamación de sus derechos señoriales en Valencia.

Pese a las circunstancias vividas, Beatriz de Lauria no solo aportó a los Ponce de León andaluces prestigio y visibilidad, sino también conciencia de linaje. Su propia presencia, junto con la activa participación militar de su esposo al servicio de Alfonso XI, aceleró la emancipación familiar de los señores de Marchena respecto a la rama leonesa y original del linaje. La actuación de Beatriz al frente de sus cada vez más exiguos señoríos, en paralelo pero no en conexión con Urraca Osorio, refuerza la percepción de la "casa de Marchena" como un núcleo autónomo y diferenciado del magma originario Guzmán-Ponce de León que María Alfonso Coronel se esforzó en mantener unido hasta muy pocos años antes de que Beatriz de Lauria pisara por primera vez Andalucía.

\section{BIBLIOGRAFÍA CITADA}

Anasagasti Valderrama, Ana María; Rodríguez Liáñez, Laureano (2006), Niebla y su tierra en la Baja Edad Media. Historia y documentos, vol. I, Huelva, Diputación de Huelva.

Arias Guillén, Fernando (2012), Guerra y fortalecimiento del poder regio en Castilla. El reinado de Alfonso XI (1312-1350), Madrid, Ministerio de Defensa - CSIC.

Ayala Martínez, Carlos de (2003), Las órdenes militares hispánicas en la Edad Media (siglos XII-XV), Madrid, Marcial Pons - Latorre Literaria.

Barrantes Maldonado, Pedro, Illustraciones de la Casa de Niebla, ed. Pascual de Gayangos, Madrid, Imprenta Nacional, 1857 (Memorial Histórico Español, 9).

Borrero Fernández, Mercedes (2004), El monasterio cisterciense de Santa María de las Dueñas. Sevilla. Siglos XIII-XVI, "Historia. Instituciones. Documentos" 31, pp. 51-68. 
Cabezuelo Pliego, José Vicente (1997), De nuevo sobre procuración, frontera y organización defensiva del reino de Valencia frente al Islam en el siglo XIV. Jaime de Jérica y Granada, en El Mediterráneo: hechos de relevancia histórico-militar y sus repercusiones en España. V Jornadas Nacionales de Historia Militar, Sevilla, Universidad de Sevilla Cátedra "General Castaños" de la Región Militar Sur, pp. 187-198.

Cabrera Muñoz, Emilio (1999), Nobleza y señorios en Andalucía durante la Baja Edad Media, en La nobleza peninsular en la Edad Media, Ávila, Fundación Sánchez Albornoz, pp. 89-119.

Carriazo Rubio, Juan Luis (2002), La memoria del linaje. Los Ponce de León y sus antepasados a fines de la Edad Media, Sevilla, Universidad de Sevilla - Ayuntamiento de Marchena.

Carriazo Rubio, Juan Luis (2003), Los testamentos de la Casa de Arcos (13741530), Sevilla, Diputación de Sevilla - Ayuntamiento de Marchena.

Carriazo Rubio, Juan Luis (2021), Álvar García de Illas: servicios diplomáticos y aspiraciones señoriales bajo el reinado de Alfonso XI de Castilla, "En la España Medieval" 44, pp. 349-371.

Costa i Paretas, Maria Mercè (1998), La casa de Xèrica i la seva política en relació amb la monarquia de la Corona d'Aragó (segles XIII-XIV), Barcelona, Fundació Noguera.

Costa i Paretas, Maria Mercè (2001), La misteriosa dama de Xèrica, "Acta historica et archaeologica medievalia" 22/2, pp. 671-678.

Crónica del rey don Alfonso el Onceno, ed. de Cayetano Rosell, en Crónicas de los reyes de Castilla, vol. I, Madrid, Atlas, 1953, pp. 171-392 (Biblioteca de Autores Españoles, 66).

Domingo Malvadi, Arantxa (2010), Disponiendo anaqueles para libros. Nuevos datos sobre la biblioteca de Jerónimo Zurita, Zaragoza, Institución "Fernando el Católico".

Fullana Mira, Luis (1923), La Casa de Lauria en el Reino de Valencia, en III Congreso de historia de la Corona de Aragón / III Congrés d'història de la Corona d'Aragó, vol. I, Valencia, Diputación Provincial Ayuntamiento de Valencia, pp. 65-164.

Garcés de Cariñena, Pedro, Nobiliario de Aragón, anotado por Zurita, Blancas y otros autores, ed. María Isabel Ubieto Artur, Zaragoza, Anubar, 1983.

García Fernández, Manuel (1985), La Hermandad General de Andalucía durante la minoría de Alfonso XI de Castilla: 1312-1325, "Historia. Instituciones. Documentos" 12, pp. 351-375.

García Fernández, Manuel (1988), Nuevos datos sobre la repoblación del sector sur de la Campiña sevillana durante el siglo XIV, en Cabrera, Emilio (coord.), Andalucia entre oriente y occidente (1236-1492). Actas del V Coloquio Internacional de Historia Medieval de Andalucía, Córdoba, Diputación Provincial de Córdoba, pp. 145-159. 
García Fernández, Manuel (1989), El reino de Sevilla en tiempos de Alfonso XI (1312-1350), Sevilla, Diputación Provincial de Sevilla.

Gómez Vozmediano, Miguel Fernando (2016), Francisco Rades de Andrada, cronista y linajista. Adiciones a la Crónica de la Orden y Cavallería de Calatrava, Madrid, CSIC.

Gómez Vozmediano, Miguel Fernando; Sánchez González, Ramón (2015), Pedro Salazar de Mendoza (1549-1629): cronista nobiliario y bruñidor de linajes, "Tiempos Modernos" 31, pp. 393-422.

González Jiménez, Manuel (1993), La repoblación de la zona de Sevilla durante el siglo XIV, Sevilla, Universidad de Sevilla.

Gran crónica de Alfonso XI, ed. de Diego Catalán, vol. II, Madrid, Gredos, 1977.

Ladero Quesada, Miguel Ángel (1973), Andalucía en el siglo XV. Estudios de historia política, Madrid, CSIC.

Ladero Quesada, Miguel Ángel (1984), De Per Afán a Catalina de Ribera. Siglo y medio en la historia de un linaje sevillano (1371-1514), "En la España Medieval" 4, pp. 447-497.

Ladero Quesada, Miguel Ángel (1992), Niebla, de reino a condado. Noticias sobre el Algarbe andaluz en la Baja Edad Media, Madrid, Real Academia de la Historia.

Ladero Quesada, Miguel Ángel (2002), María Alfonso Coronel, matriarca sevillana, en los comienzos de la Casa de Guzmán (1267-1331), en Reglero de la Fuente, Carlos M. (coord.), Poder y sociedad en la Baja Edad Media hispánica. Estudios en homenaje al profesor Luis Vicente Díaz Martín, vol. I, Valladolid, Universidad de Valladolid, pp. 427-460.

Ladero Quesada, Miguel Ángel (2015), Guzmán. La casa ducal de Medina Sidonia en Sevilla y su reino. 1282-1521, Madrid, Dykinson.

López de Ayala, Pero, Crónica del rey don Pedro y del rey don Enrique, su hermano, hijos del rey don Alfonso Onceno, ed. de Germán Orduna, estudio preliminar de Germán Orduna y José Luis Moure, Buenos Aires, SECRIT, 1994-1997.

Martínez de Aguirre Aldaz, Javier (1992), El refectorio de San Agustín y la asimilación del gótico en Sevilla, "Archivo Hispalense” 229, pp. 109-129.

Moxó y Montolíu, Francisco de (1982), La relación epistolar entre Alfonso XI y Alfonso IV en el Archivo de la Corona de Aragón, "En la España Medieval" 3, pp. 173-195.

Moxó y Montolíu, Francisco de (1986), La política aragonesa de Alfonso XI y los hijos de Leonor de Guzmán, "En la España Medieval" 5/2, pp. 697-708. Moxó y Montolíu, Francisco de (1988), Cartas reales de Alfonso XI a Pedro IV en el Archivo de la Corona de Aragón, "Anuario de Estudios Medievales" 18 , pp. 275-287. 
Novoa Portela, Feliciano (2003), Algunas consideraciones sobre los Maestres alcantarinos desde el nacimiento de la Orden hasta 1350, "Revista de Estudios Extremeños" 59/3, pp. 1059-1081.

Ortiz de Zúñiga, Diego (1988), Anales eclesiásticos y seculares de la muy noble y muy leal ciudad de Sevilla, metrópoli de la Andalucía, vol. II, Sevilla, Guadalquivir.

Paz y Melia, Antonio (1915), Series de los más importantes documentos del Archivo y Biblioteca del excmo. señor duque de Medinaceli, elegidos por su encargo y publicados a sus expensas por A. Paz y Mélia. I. ${ }^{a}$ serie. Histórica. Años 860-1814, Madrid, Archivo y Biblioteca de la Casa de Medinaceli.

Rades y Andrada, Francisco de, Chrónica de Alcántara, en Chrónica de las tres órdenes y cauallerías de Sanctiago, Calatraua y Alcántara, Toledo, Juan de Ayala, 1572.

Salazar de Mendoza, Pedro, Crónico de la excelentíssima Casa de los Ponçes de León, Toledo, Diego Rodríguez, 1620.

Serrano y Pineda, Luciano (1915), Alfonso XI y el papa Clemente VI durante el cerco de Algeciras, "Cuadernos de trabajos de la Escuela Española de Arqueología e Historia de Roma" 3, pp. 1-33.

Taylor, Barry (1986), Don Jaime de Jérica y el público de El conde Lucanor, "Revista de Filología Española" 66/1-2, pp. 39-58.

Torremocha Silva, Antonio (1994), Algeciras entre la Cristiandad y el Islam. Estudio sobre el cerco y conquista de Algeciras por el rey Alfonso XI de Castilla, así como de la ciudad y sus términos hasta el final de la Edad Media, Algeciras, Instituto de Estudios Campogibraltareños.

Trenchs Ódena, José (1980), La comitiva de Alfonso XI: notas para su estudio, "Saitabi" 30, pp. 11-19.

Ubieto Artur, María Isabel (1986), El Nobiliario de Aragón de Pedro Garcés de Cariñena, fuente desconocida por la historiografia actual, utilizada por el cronista Jerónimo Zurita, en Jerónimo Zurita. Su época y su escuela, Zaragoza, Institución "Fernando el Católico", pp. 137-142.

Vázquez Campos, Braulio (2006), Los adelantados mayores de la frontera o Andalucía (siglos XIII-XIV), Sevilla, Diputación de Sevilla.

Villarroel González, Óscar (2018), La formación de los diplomáticos en la Castilla bajomedieval, "Studia Historica. Historia Medieval" 36/2, pp. 117-146.

Zurita, Jerónimo, Anales de Aragón, ed. de Ángel Canellas, vols. III (libros VI-VII), IV (libros VIII-X), Zaragoza, Institución "Fernando el Católico", 1978.

Fecha de recepción del artículo: junio 2020

Fecha de aceptación y versión final: febrero 2021 